\title{
Experimental Investigation of a 2D Supercritical Circulation-Control Airfoil Using Particle Image Velocimetry
}

\author{
Gregory S. Jones*, Chung-Sheng Yao ${ }^{\dagger}$, and Brian G. Allan ${ }^{*}$ \\ NASA Langley Research Center, Hampton, Virginia, 23681
}

\begin{abstract}
Recent efforts in extreme short takeoff and landing aircraft configurations have renewed the interest in circulation control wing design and optimization. The key to accurately designing and optimizing these configurations rests in the modeling of the complex physics of these flows. This paper will highlight the physics of the stagnation and separation regions on two typical circulation control airfoil sections.
\end{abstract}

\section{Nomenclature}

\begin{tabular}{|c|c|c|c|}
\hline A & area & $\mathrm{TE}$ & trailing Edge \\
\hline $\mathrm{b}$ & 2D airfoil span & TI & turbulence intensity \\
\hline$c_{1}$ & section lift coefficient & $\mathrm{T}$ & static temperature \\
\hline $\mathrm{C} \mu$ & momentum coefficient & $\mathrm{w}$ & slot width \\
\hline $\mathrm{c}$ & chord & $\alpha$ & angle of attack \\
\hline $\mathrm{CC}$ & Circulation Control & $\beta$ & turbine flow meter coefficients \\
\hline CTOL & Conventional Take Off \& Landing & $\delta_{\text {JET }}$ & jet thrust angle (ref. normal to jet exit) \\
\hline ESTOL & Extreme Take Off \& Landing & $\Gamma$ & circulation \\
\hline GACC & General Aviation Circulation Control & $\theta_{\mathrm{JET}}$ & jet separation angle \\
\hline $\mathrm{h}$ & slot height at jet exit & $\rho$ & density \\
\hline $\mathrm{H}$ & tunnel height & $\sigma_{\mathrm{v}}$ & standard deviation of PIV velocity \\
\hline LE & leading edge & & \\
\hline 1 & airfoil section lift & \multicolumn{2}{|c|}{ Subscripts: } \\
\hline M & mach number & $\infty$ & free stream conditions \\
\hline $\mathrm{m}$ & mass flow & JET & jet at slot exit \\
\hline NPR & nozzle pressure ratio $=\mathrm{P}_{0} / \mathrm{P}_{\infty}$ & duct & duct stagnation condition \\
\hline $\mathrm{P}$ & pressure & 0 & stagnation conditions \\
\hline PIV & $\begin{array}{l}\text { Particle Image Velocimetry } \\
\text { trailing edoe rous }\end{array}$ & & \\
\hline $\begin{array}{r}\mathrm{r} \\
\mathrm{U}\end{array}$ & $\begin{array}{l}\text { tralling edge radius } \\
\text { horizontal mean velocity component }\end{array}$ & & \\
\hline $\mathrm{V}$ & vertical mean velocity component & & \\
\hline $\mathrm{u}$ & horizontal velocity fluctuation & & \\
\hline $\mathrm{v}$ & vertical velocity fluctuation & & \\
\hline $\mathrm{q}$ & dynamic pressure & & \\
\hline & wing planform area & & \\
\hline SCFM & standard mass flow (referenced to 14 . & $\& 7$ & \\
\hline
\end{tabular}

\footnotetext{
${ }^{*}$ Senior Scientist, Flow Physics \& Control Branch, M/S 170, and AIAA Senior Member.

${ }^{\dagger}$ Senior Scientist, Flow Physics \& Control Branch, M/S 170.

${ }^{*}$ Research Scientist, Flow Physics \& Control Branch, M/S 170, and AIAA Senior Member
} 


\section{Introduction}

$\mathrm{I}_{\mathrm{w}}^{\mathrm{n}}$ nterest in circulation control (CC) aerodynamics has recently increased for both military and civil applications with emphasis on providing better vehicle performance and prediction capability ${ }^{1}$. These demands are not only focused on performance and economic value, but are also related to new and stringent regulations associated with reduced airport noise and environmental issues. NASA and the FAA have made the latter issues a top priority in developing technologies required for optimization of near airport operations as described by NASA's ESTOL program. The ESTOL vehicle goals were first formulated from an industry, academic, and government agency workshop held in Reno, Nevada, in January 2003. The purpose of this workshop was to define vehicle capabilities of interest to all partners, then to define the technical challenges that are barriers to achieving those capabilities today. The capabilities defined by this effort were based on a $50-150$ passenger (nominally 100 passenger) aircraft. A notional concept vehicle is shown in Fig. 1.

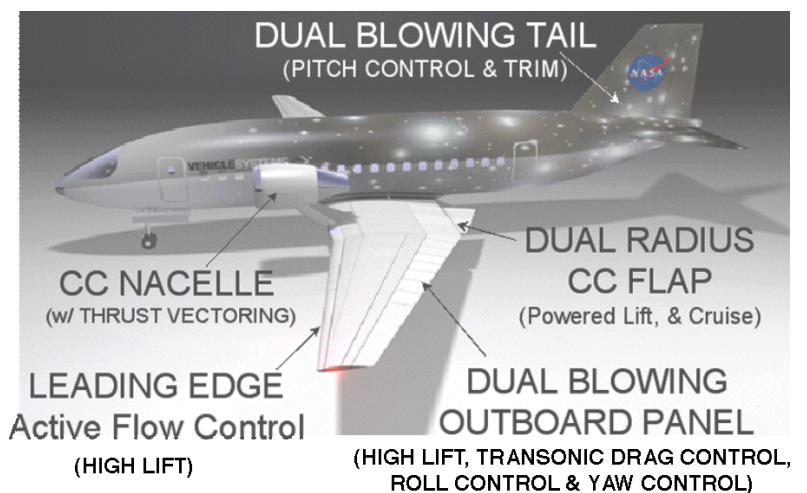

Figure 1. Notional NASA ESTOL 100 passenger vehicle with CC opportunities.

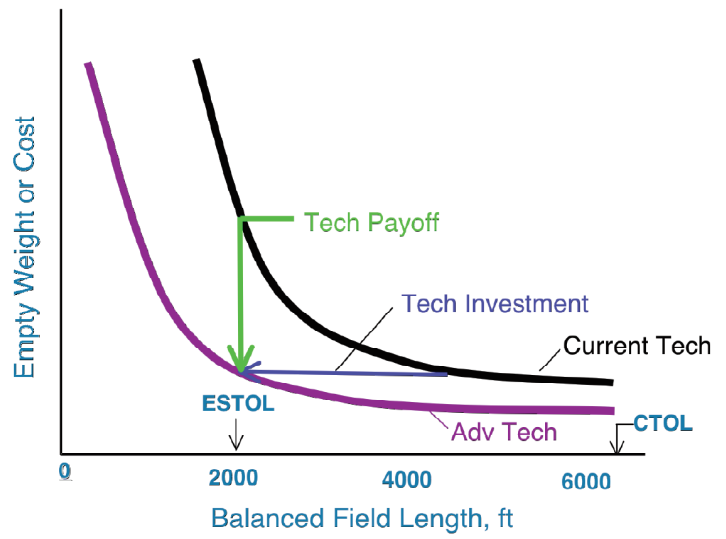

Figure 2. Performance benefit of technology applied to ESTOL type aircraft.

\section{Nominal Capabilities of an ESTOL aircraft}

- Balanced field length of 2000 feet

- $\quad$ Efficient cruise at Mach 0.8

- Takeoff and landing speeds less than 50 knots

- Turn radius in terminal area less $0.25 \mathrm{~nm}$

- $1400-2000$ mile range

- Noise footprint within the airport boundary

The emphasis of low speed take-off and landing on a $2000 \mathrm{ft}$. balanced field runway, shown in Fig. 2, initially identified a maximum lift of 10 while efficient cruise at Mach 0.8 required a lift to drag ratio near $25 .^{2}$ Simultaneous realization of all of these capabilities does not appear possible using conventional high-lift systems and prompted an interest in circulation control (CC) concepts for the ESTOL configuration.

Participants at the 2004 NASA/ONR Circulation Control Workshop ${ }^{3}$ highlighted the inconsistencies of Computational Fluid Dynamics (CFD) predictions and a lack of modern experimental databases that could be used for code validation purposes. Many of the workshop participants suggested that the technology readiness level for circulation control has transitioned from basic science and technology to research and development (or applied engineering). Others said that circulation control performance cannot be reliably predicted and more basic research that focuses on the physics of Coanda surface jet separation and turbulence modeling is needed. Both are correct. Engineers can design CC wings that typically fall into two classes of $\mathrm{CC}$ airfoils, either elliptic or supercritical geometries. ${ }^{4,5,6}$

However, optimizing a CC airfoil for a specific mission still requires significant experimental testing and verification. ${ }^{8,9,10}$ Development of more advanced CFD tools for improved prediction of CC airfoils would significantly reduce the aircraft design cycle time. Currently these advanced CFD tools are inconsistent and often over predict CC airfoil performance. Therefore detailed experimental data are needed to identify the physics that are being misrepresented in the codes. ${ }^{11,12,13}$

The global effects of modifying the circulation characteristics around the airfoil are captured in the integrated force, moment, and surface pressure profiles. To minimize the $3 \mathrm{D}$ effects on the model, a large span to chord ratio is desired. An additional technique used to minimize 3D effects removes the influence of the sidewall juncture flow through blowing or suction on the sidewalls. In addition to minimizing the $3 \mathrm{D}$ effects it is necessary to account for 
the influence of the wall interference, e.g. model blockage, and streamline curvature. This can be achieved by a large wind tunnel cross section to model frontal area ratio. It should be noted that traditional ratios are based on the physical size of the model and do not account for the pneumatic flap. Both of these problems, juncture flows and wall interference, are compounded by large streamline turning associated with super-circulation and high-lift configurations typical of circulation control. ${ }^{14}$ An alternative to experimental facility corrections is to use CFD tools that model the CC airfoil and the solid wind tunnel walls. Two-dimensional CFD analysis was used to gain a better understanding of the wind tunnel wall interference for this study.

This paper will focus on the physics of high-lift CC experiments that identify Coanda separation and the associated performance of a 2D supercritical airfoil with two different Coanda surfaces as shown in Fig. 3. Insight into these results are intended to provide understanding of physics related to advanced circulation control geometries. To minimize the issues of identifying the exact Coanda separation, a Coanda flap that fixed the jet separation to a known location was tested. A second trailing edge configuration with a rounded Coanda surface allowed separation to move with varying jet mass flows. These experiments emphasize flow-field data using a 2component Particle Image Velocimetry (PIV) system that characterized the circulation (flow turning) related to pneumatic flow control. Since the focus of this effort is to provide physics data for circulation control configurations, there was no effort to maximize the performance of either airfoil.

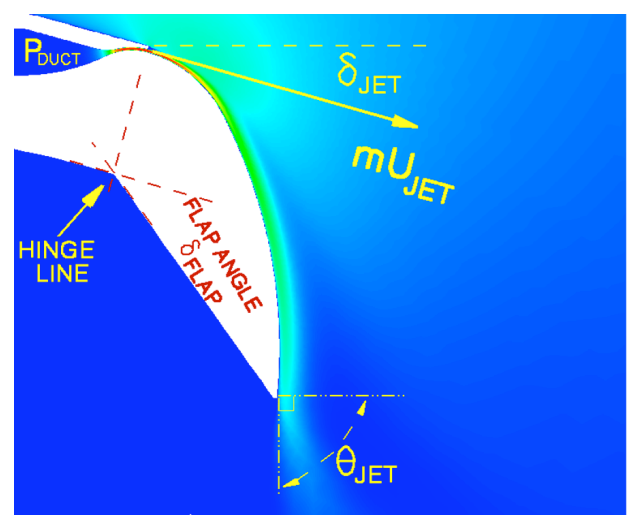

(a) Flap Configuration

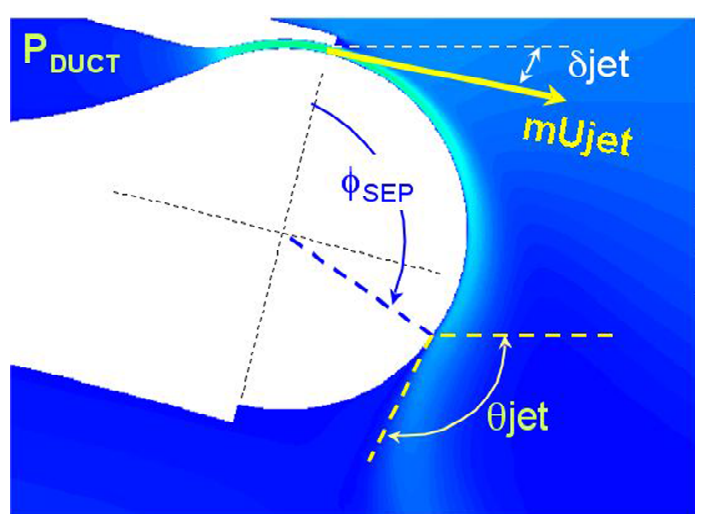

(b) Circular configuration

Figure 3. Comparison of flow field characteristics for two Coanda surfaces.

\section{Experimental Setup}

\section{A. Wind tunnel and circulation control model}

The experimental results were obtained for the General Aviation Circulation Control (GACC) airfoil ${ }^{15}$ in the open return NASA Langley Basic Aerodynamic Research Tunnel $(B A R T){ }^{16}$ shown in Fig. 4. The results described in this report are from the third entry of a test series intended to capture the flow field and the physics of two circulation control geometries, a $2 \%$ circular trailing edge and a $7 \%$ hinged CC flap, Fig. 5. The verification process of this test series has resulted in several observations that refine and improve these results. This test was conducted over a Mach number range of 0.08 to 0.1

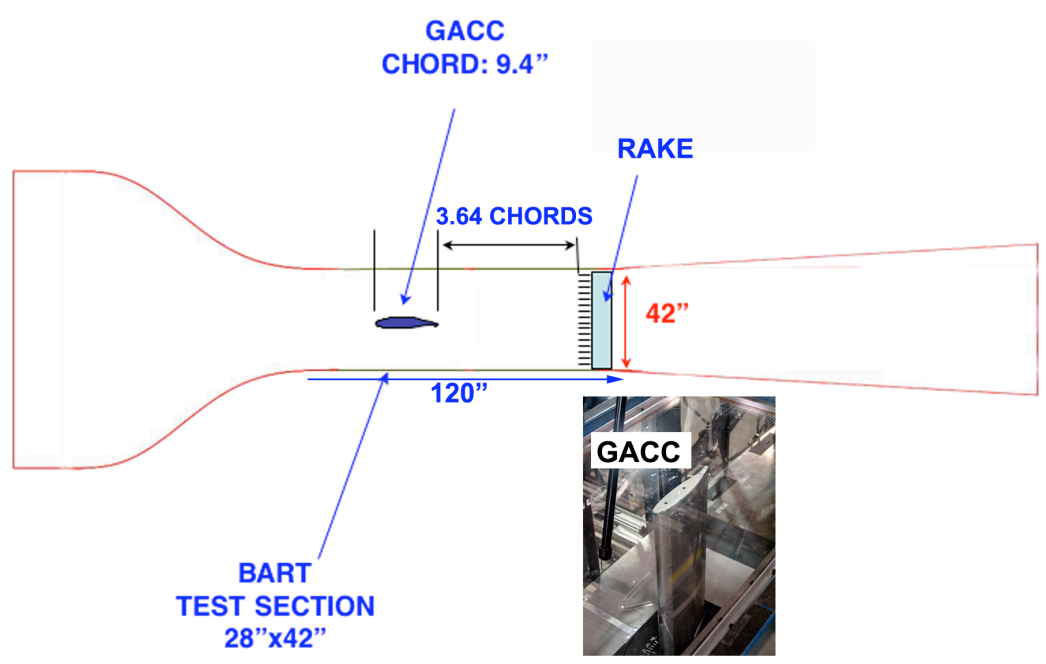

Figure 4. Sketch and photo of GACC mounted in BART. 
corresponding to dynamic pressures of $10 \mathrm{psf}$ and $15 \mathrm{psf}$ respectively. Performance results described in Ref. 17 and 18 include lift, drag, pitching moment, yawing moment, and rolling moment obtained from a 5-component strain gage balance. Airfoil surface pressure measurements were obtained mid-span on the airfoil.
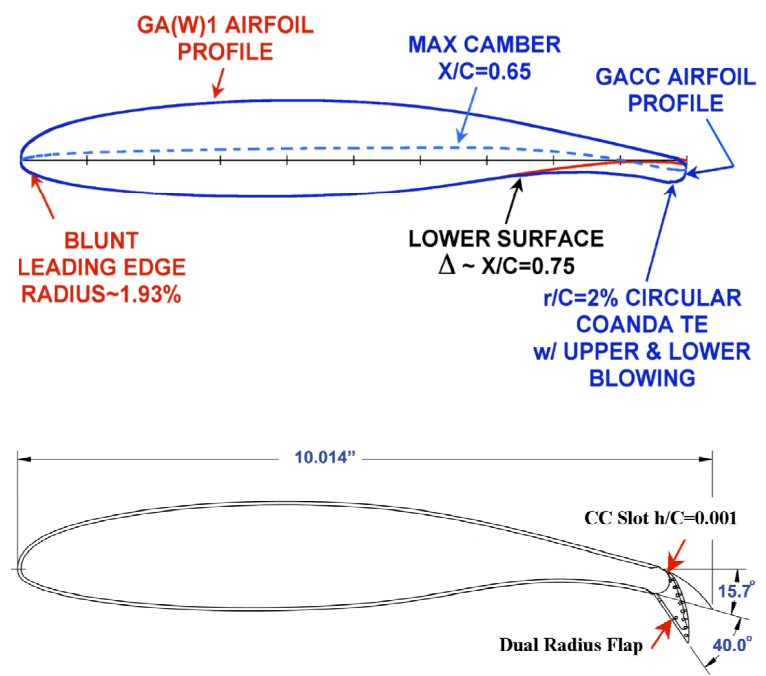

Figure 5. Circulation control airfoil geometries having circular and flap type trailing edges.
1. Jet slot height and Momentum Coefficient calculations

Circulation control performance for a 2D airfoil is typically characterized by the thrust or momentum coefficient:

$$
\begin{aligned}
& \mathrm{C} \mu=\frac{\text { THRUST }}{\mathrm{qS}}=\frac{2 \mathrm{hw}}{\mathrm{Cb}} \frac{\rho_{\mathrm{JET}}}{\rho_{\infty}} \frac{\mathrm{U}_{\text {JET }}^{2}}{\mathrm{U}_{\infty}^{2}} \\
& \mathrm{C} \mu=\frac{\text { THRUST }}{\mathrm{qS}}=\frac{\mathrm{mU} \mathrm{JET}_{\mathrm{JET}}}{\mathrm{qS}} \\
& \text { where } \\
& \mathrm{m}=\rho_{\mathrm{JET}} \mathrm{U}_{\mathrm{JET}}(\mathrm{h})(\mathrm{w}) \\
& \text { and }
\end{aligned}
$$

$$
\mathrm{U}_{\mathrm{JET}}=\sqrt{\frac{2 \gamma \mathrm{R}\left(\mathrm{T}_{0 \mathrm{JET}}\right)}{\gamma-1}\left(1-\left(\frac{\mathrm{P}_{\infty}}{\mathrm{P}_{0 \mathrm{JET}}}\right)^{\frac{\gamma-1}{\gamma}}\right.}
$$

The sensitivity of the airfoil performance to $C \mu$ is dependent on the jet characteristics and the airfoil geometry, particularly the Coanda surface. Inspection of Eqs. 1 and 2 highlights two approaches for obtaining $\mathrm{C} \mu$. The experimental data described in this paper had jet exit conditions that ranged from Mach numbers of 0.1 to sonic conditions, but were concentrated at $\left(\mathrm{Ujet} / \mathrm{U}_{\infty}\right)^{2}$ from 20 to 80 , which corresponds to mass flows ranging from 0.05 $\mathrm{lbm} / \mathrm{sec}$ to $0.13 \mathrm{lbm} / \mathrm{sec}$ for a nominal slot height of $0.010 \mathrm{inch}$. Figure 6 illustrates the sensitivity of the momentum coefficient and mass flow to the slot height measurement error. For example, a slot measurement error of \pm 0.001 inch would result in an error in mass flow of $20 \%$ at $\left(\mathrm{Ujet} / \mathrm{U}_{\infty}\right)^{2}$ of 50 . Using Eq. 2 simplifies the required

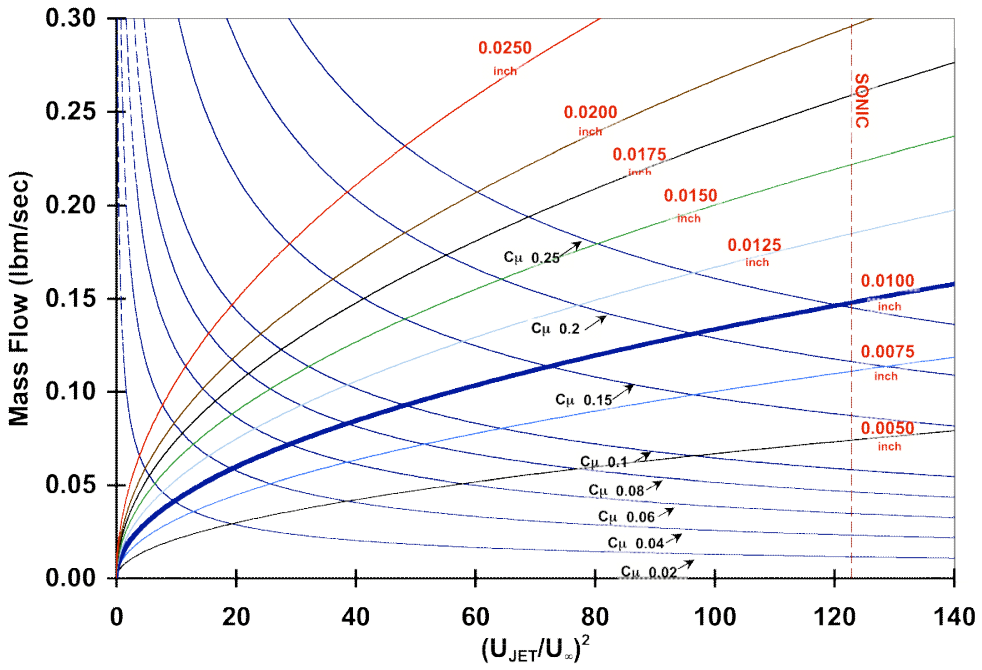

Figure 6. Momentum coefficient sensitivity to slot height and jet velocity, $q=10 \mathrm{psf}, \mathrm{To}=\mathbf{7 2}^{\circ} \mathrm{F}$, chord $=10.014$ inch . measurements for determining $\mathrm{Cu}$ and eliminates the need to measure slot height and jet density for the calculation of momentum coefficient.

Slot height is a critical parameter to the airfoil setup and was given careful attention. Inserting a 0.010 inch piano wire at the slot exit and clamping it in place by pulling down on the model skin with screws was used to fix the slot to a uniform height along the span. Routine inspection of the slot revealed that the piano wire could be blown out of the slot, allowing the slot height to vary locally $\pm 20 \%$ of the desired slot height. These piano wire standoffs were replaced when necessary and conditions were repeated. An example of missing standoffs is shown in Fig. 7. The slot height measurements (feeler gage accuracy \pm 0.001 inch) highlight 
the slot conditions for missing standoffs at $\mathrm{Z} / \mathrm{C}=0.65$ and 0.61 . The average measured slot height with all standoffs in place was $0.0091 \mathrm{inch}$. This is inconsistent with the standoff diameter of $0.010 \pm 0.0002 \mathrm{inch}$. The confidence of the slot measurement can be biased \pm 0.001 inch based on the inaccuracy of the measurement.

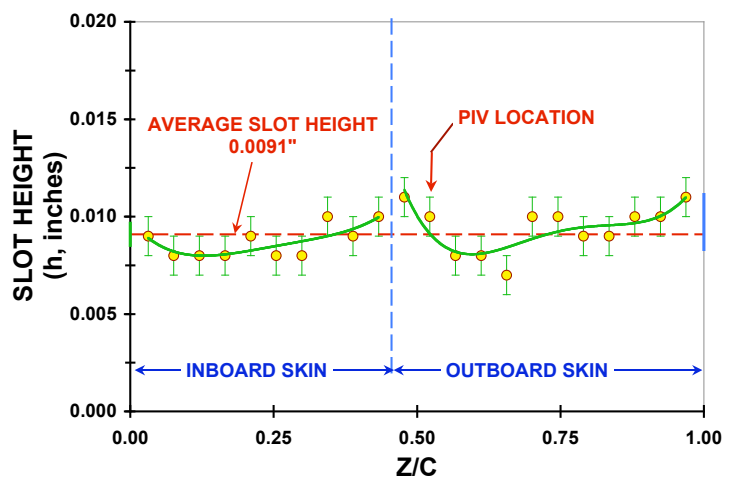

Figure 7. Slot height variations along the span.

\section{2. $3 D$ effects}

For a $2 \mathrm{D}$ experiment, it is assumed that the jet velocity is constant along the span. The validity of this $2 \mathrm{D}$ assumption is affected by three factors; internal flow nonuniformity to the slot exit, non-uniform slot height along the span, and wind tunnel wall interference effects, (e.g. juncture region effects, and model blockage effects). The slot height was fixed for both geometries at $0.010 \mathrm{inch}$, corresponding to $\mathrm{h} / \mathrm{C}$ of 0.001064 for the circular Coanda surface and 0.00100 for the CC flap Coanda surface.

Slot height variation along the span causes a nonuniform jet exit velocity along the span. However, a slot height of $0.010 \pm 0.001$ inch corresponds to the $2 \mathrm{D}$ plane where the PIV measurements were made. The velocity measurements were consistent with the averaged velocity calculated from the pressure ratio measured at 4 jet exit locations along the span. The 0.005 inch ID (0.010 inch OD) tubing used for these total pressure measurements were located in the jet exit and also acted as an additional standoff.

\section{Flow Control System}

The 350-psig air delivery system used to supply the model with high volumetric flow was temperature controlled to minimize the effects of density. Turbine type mass flow meters were used to measure the total mass flow rate to the Coanda jet. These flow meters come with a manufacturer specification of a $1 \%$ full-scale accuracy at standard atmospheric conditions, SCFM. However, this accuracy is based on ideal laminar flow conditions that require long and straight inlet and exit plumbing. The system accuracy is degraded at nonatmospheric conditions. An in-situ system calibration was performed for the text matrix pressure conditions. The sensitivity of the mass flow system was determined, and evaluated for linearity. Errors are shown in Fig. 8 to approach 5\% in the range of interest when a linear fit is used. This was improved to $2 \%$ by applying a multiple non-linear regression of the type shown in Eq. (4):

$\mathrm{lb} / \mathrm{sec}=\beta_{0}+\beta_{1} \mathrm{x}_{1}+\beta_{2} \mathrm{x}_{1}^{2}+\beta_{3} \mathrm{x}_{2}+\beta_{4} \mathrm{x}_{2}^{2}+\beta_{5} \mathrm{x}_{1} \mathrm{x}_{2}$

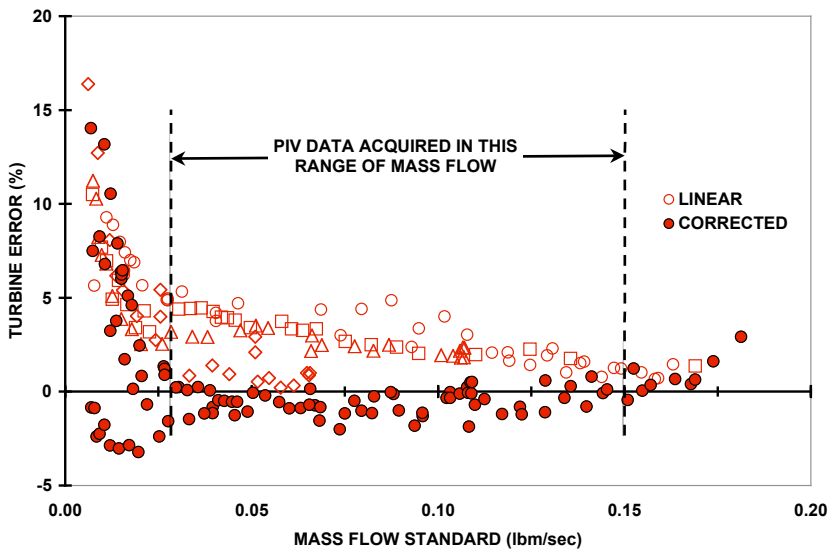

Figure 8. Turbine mass flow meter errors.

where $\mathrm{x}_{1}=$ Turbine pressure and $\mathrm{x}_{2}=$ Turbine RPM 


\section{B. Particle Image Velocimetry Measurements}

The two-component PIV system includes two $1280 \times 1024$ pixels CCD cameras and a pulsed laser installed on a scanning platform to measure the two dimensional flow field at multiple stations at the leading edge, trailing edge, and the upper surface of the airfoil model (Fig. 9). Each PIV camera was installed with a $50 \mathrm{~mm}$ macro lens which covers a field view about $150 \mathrm{~mm} \times 120 \mathrm{~mm}$ at the test section. The camera magnification was calibrated using a grid target aligned with the laser sheet. The calibration accuracy of the measurement volume dimension was within $0.1 \%$ or \pm 1 pixel over 1000 pixels. The double-pulsed Nd-Yag laser, running at $10 \mathrm{~Hz}$ and $100 \mathrm{~mJ}$ energy output, projected a light sheet between 2.5 to $3.0 \mathrm{~mm}$ thick and of $300 \mathrm{~mm}$

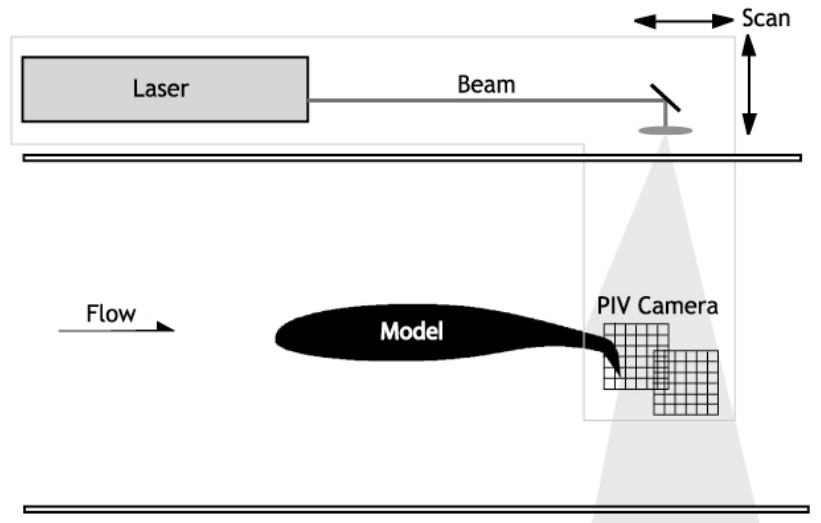

Figure 9. Sketch of PIV system setup. wide to illuminate the measurement area covered by two PIV cameras mounted in tandem. The test section was seeded by smoke particles generated from a smoke generator using commercial smoke fluids. Particle sizes were measured to be between $0.7 \sim 1.0 \mu \mathrm{m}$. The interrogation resolution of the PIV measurement volume was set between 28 to 32 pixels corresponding to about $3.2 \mathrm{~mm}$ in physical dimension at the measurement area. Velocity fields were interrogated over a mesh of $100 \times 80$ grids, carrying about $50 \%$ overlapping of the individual grid volume. The near surface PIV measurements were limited due to a lack of seeding and/or high reflections near the surface.

Flow-field statistics, including mean and variance were computed based on 400 PIV samples. Figure 10 shows an example of the convergence of the estimation of the means and second order moments at the location of peak
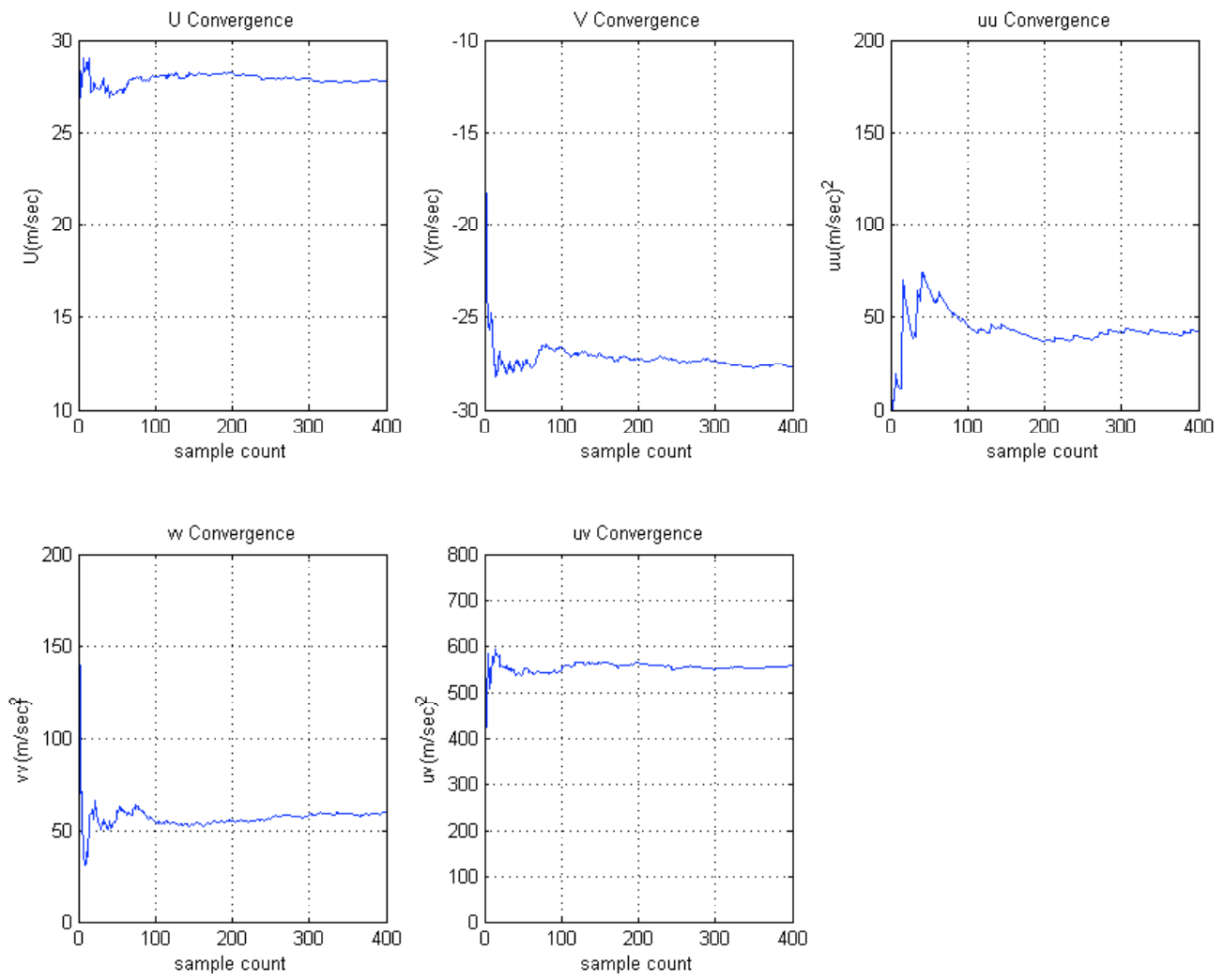

Figure 10. Convergence of statistics estimations based on 400 PIV samples. 
fluctuation in the wake with blowing of $\mathrm{C} \mu=0.016$. The uncertainties of the mean velocity estimation are within $2.5 \%$, based on $\sigma_{\mathrm{N}} / \mathrm{N}^{0.5}, \sigma_{\mathrm{N}}$ being the standard deviation of the velocity component. These uncertainties include, but are not limited to, errors associated with interrogation techniques, pixel-locking, displacement gradients, and background noise. . $^{192}$

The seeding particles coated the optical window at the juncture of the model and window. The rate of contamination was dependent on the blowing condition, i.e., higher blowing conditions resulted in more window contamination therefore more frequent window cleaning. An example of measurement repeatability is highlighted by the PIV data shown in Fig. 11. The differences in the jet region are related to the errors associated with resetting the mass flow conditions after a shutdown and restart of the experiment.

\section{Data and Analysis}

There are two distinct flow control regimes that define circulation control as a function of blowing. ${ }^{1,3}$ These distinct regimes are commonly referred to as separation control and super-circulation control and exhibit different global efficiencies as determined by change in unit lift due to change in unit blowing. The physical description of the efficiencies of these regimes is demonstrated by the relationship of the jet separation location on the trailing edge surface and the interaction of the jet with the on-coming flow. As the jet separation location moves around the Coanda trailing edge surface, the leading edge stagnation region moves aft and the effective aft stagnation moves forward, increasing the circulation and lift around the airfoil. Circulation affects lift, drag, and pitching moment, yielding performance levels consistent with ESTOL requirements. The transition from one regime to another is not always clearly identified and is dependant on the sharpness of the trailing edge.

A major roadblock to predicting the performance of circulation control geometries is to accurately predict the separation location of the jet on the trailing edge surface. The following sections highlight two geometries, a Coanda flap trailing edge and a Coanda circular trailing edge.

\section{A. Circulation Control Flap Geometry}

\section{PIV data}

The global effects of circulation control are characterized by the streamlines around the entire airfoil. The PIV data were acquired in sections that were separated in time by as much as several weeks. The data for a given section or measurement location could take as long as 20 minutes to acquire and store. Wind tunnel and jet conditions varied less than $1 \%$ for this 20 -minute period. PIV measurements were obtained for many blowing conditions at a fixed location. Upon completion of the blowing matrix, the measurement volume was moved to a different location, and then the blowing matrix was repeated. This process occurred over a several weeks. During this period, the wind tunnel and jet conditions could vary up to $\pm 2 \%$. These variations are observed as apparent discontinuities in streamlines, turbulence quantities, etc., when combining the different PIV data sets. This is most evident at the boundaries of the different measurement sections. Instead of averaging the jet momentum coefficients for the composite PIV data, it was determined to report only the jet characteristics of the PIV sector that captured the flow closest to the jet exit and Coanda surface.

Figure 12 shows the lift performance of the CC flap geometry with corresponding PIV data. The boundaries of separation control and super-circulation control are historically based on the change in lift efficiency as a function of momentum coefficient. The transition of separation control to super-circulation control is difficult to quantify with this approach. Results of this experiment will refine this approach by identifying the end of the separation control regime to the jet separation located at the most aft portion of the CC flap and correlating it to the performance of the airfoil. A series of composite of PIV mean velocity flow fields are shown in Fig. 13 and identifies the end of separation control for this configuration to be at a $\mathrm{C} \mu$ of 0.029 . 


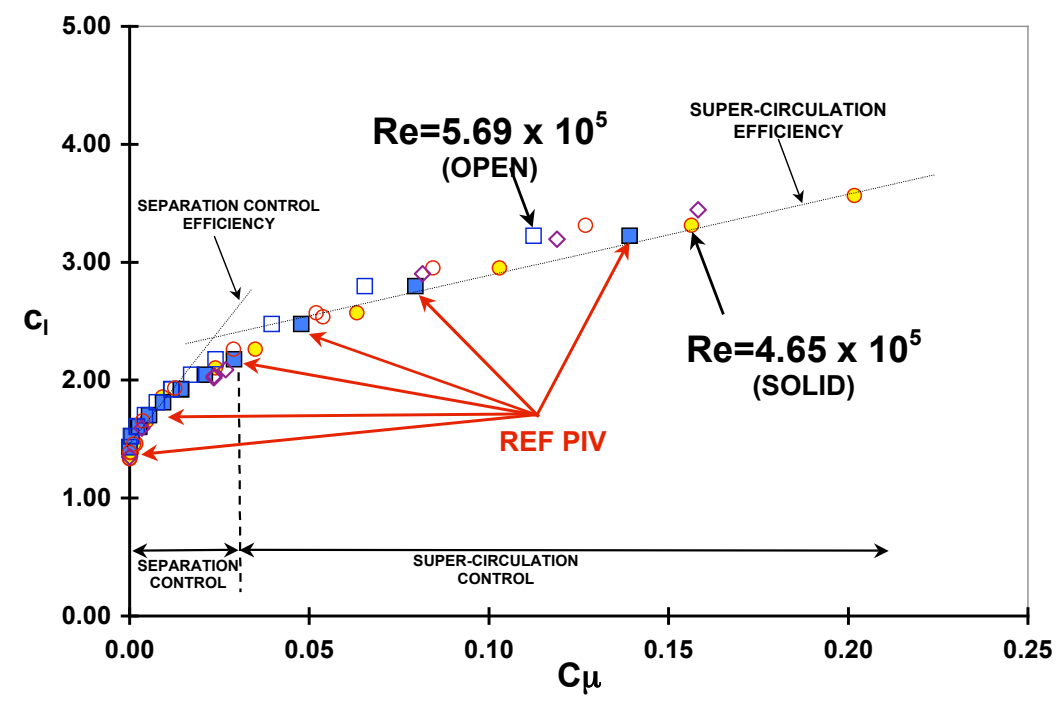

Figure 12. Lift performance of the CC flap geometry, identifying corresponding PIV data, $\alpha=0^{\circ}$.

PIV measurements near the trailing edge highlight the transition from separation control to super-circulation control as shown in Fig. 14. The jet details near the surface were limited due to insufficient particle seeding in the jet and/or high reflections near the surface. The velocity ratio displayed is based on the magnitude of the measured mean PIV U-component and V-component and the measured wind tunnel free-stream velocity as defined by Eq. 5 .

$$
\frac{|\bar{U}|}{U_{\infty}}=\frac{\sqrt{U^{2}+V^{2}}}{U_{\infty}}
$$

As the blowing is increased the separated flow is entrained and mixed with the jet (separation control) as shown in Fig. 14a and 14b. This continues until the jet separation is extended to the most aft location on the flap, Fig. 14c. The streamlines continue to turn as the jet penetrates the lower flow field (super-circulation control) shown in Fig. $14 \mathrm{~d}$ and $14 \mathrm{e}$. The conditions described here are further illustrated by the comparison of sectional lift coefficient as a function of blowing coefficient in Fig. 12. The description based on the PIV flow field data combined with the lift curve confirm the higher efficiency of the blowing in the separation control regime and the lower blowing efficiency in the super-circulation regime.

Another approach to compare the efficiency of the $\mathrm{CC}$ system throughout the range of blowing coefficients is to consider the unsteady quantities of the velocity components. To do this comparison, a measure of the turbulence intensity is calculated based on the magnitude of the standard deviation of the measured PIV U-component and Vcomponent and the measured wind tunnel free-stream velocity and based on Eq. 6.

$$
\mathrm{TI}=\frac{\sqrt{\overline{\mathrm{u}^{2}}+\overline{\mathrm{v}^{2}}}}{\mathrm{U}_{\infty}}
$$

Turbulence characteristics shown in Fig. 15 and 16 highlight the bound region of the jet as it propagates through the near field wake. The magnitude of the turbulence intensity in the wake region decreased as blowing is increased in the separation control regime (Fig. 15a and 15b). The turbulence intensity and associated Reynolds shear stress throughout the flow field is minimized at the condition that corresponds to the end of separation control or as the jet separation location has just reached the most aft region of the flap, Fig. 15c and 16c. The turbulence intensity corresponding to the jet begins to increase again as the blowing is increased in the super-circulation regime, Fig. 15d and $15 \mathrm{e}$. The increase in unsteady quantities shown in the PIV flow field data is correlated to a decrease in circulation efficiency with respect to blowing shown in Fig. 12. Additionally, a large turbulent region appears approximately 1.4 chord lengths downstream of the trailing edge and can be seen in both the turbulence and Reynolds stress data shown in Fig. 15 and 16. This is possibly related to a far field coherent shear layer beginning to form. 


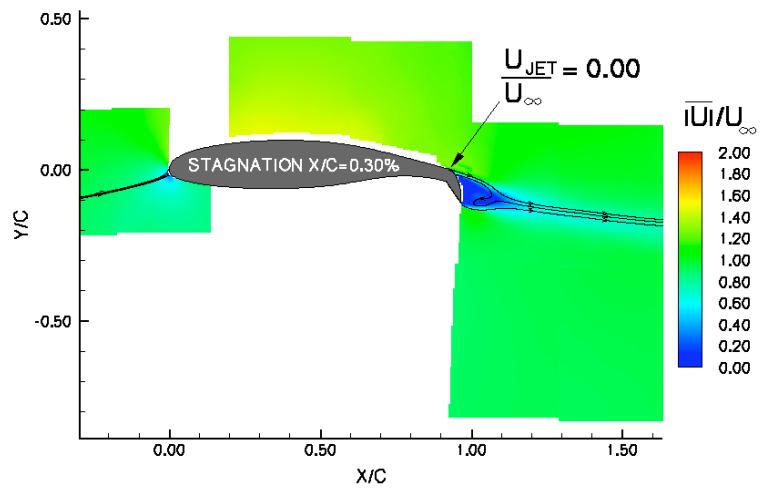

(a) $\mathrm{C} \mu=0.000$ No Blowing

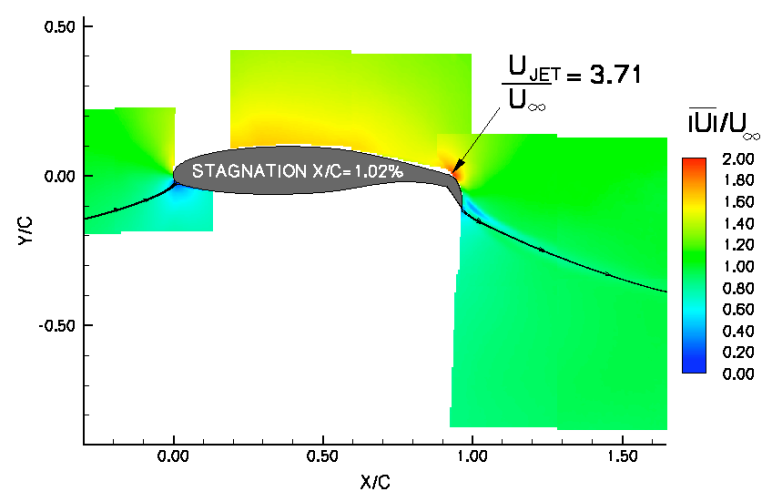

(c) $\mathrm{C} \mu=0.029$ (End of separation control)

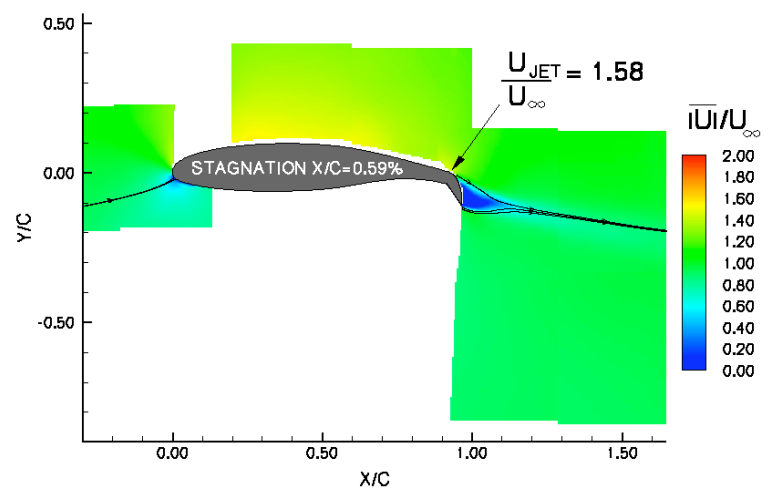

(b) $\mathrm{C} \mu=0.003$ (separation control)

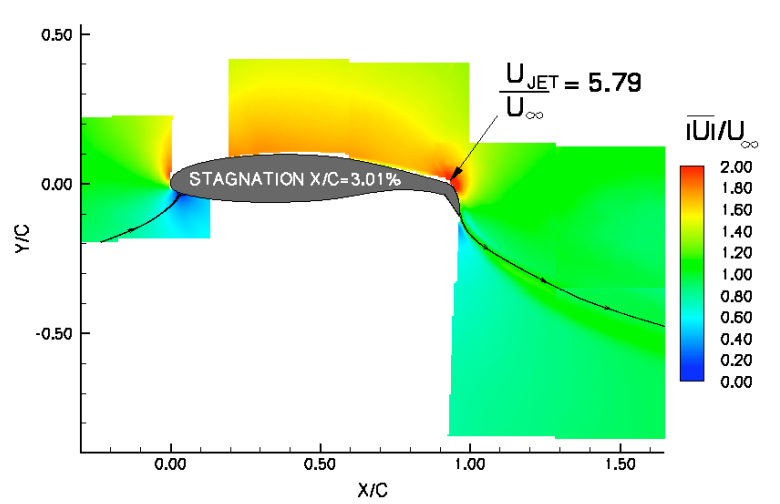

(d) $\mathrm{C} \mu=0.084$ (super-circulation control)

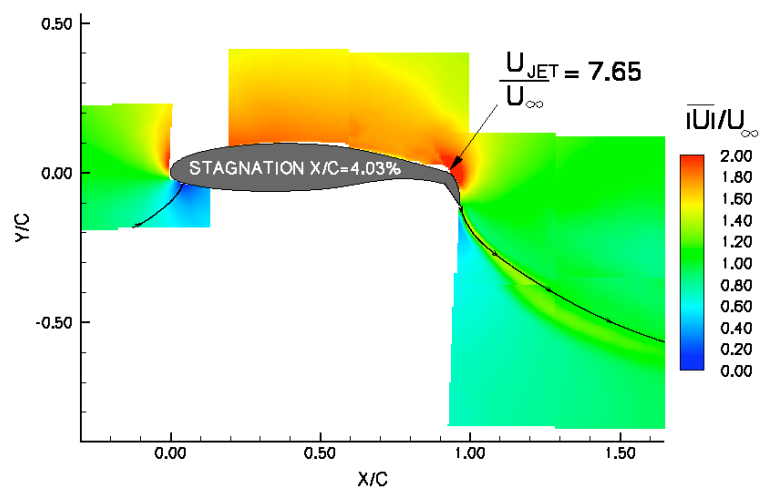

(e) $\mathrm{C} \mu=0.158$ (super-circulation control)

Figure 13. PIV streamlines and velocity magnitude for the GACC airfoil with a circulation control flap, $\mathrm{X} / \mathrm{C}_{\mathrm{JET}}$ EXIT $=0.92, \delta_{\mathrm{FLAP}}=40^{\circ}, \mathrm{h} / \mathrm{C}=0.0010$ and $\mathrm{AOA}=0.0$ degrees. 


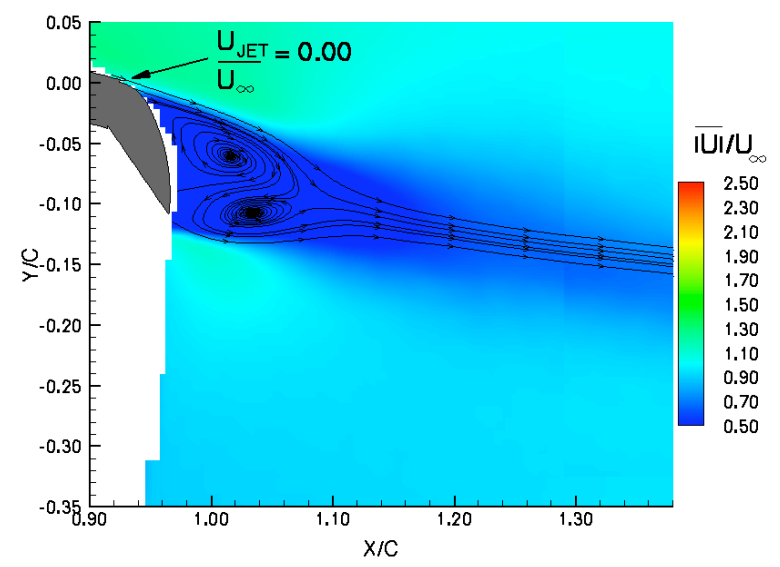

(a) No Blowing

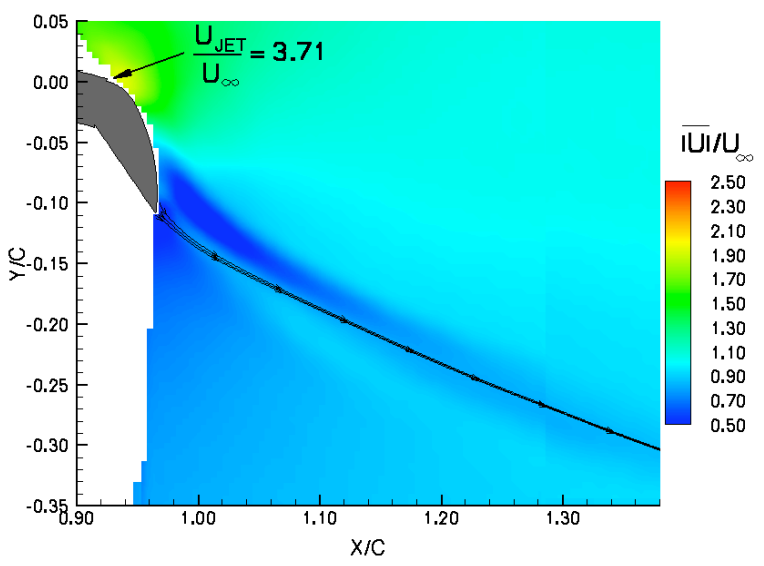

c) $\mathrm{C} \mu=0.029$ (End of separation control)

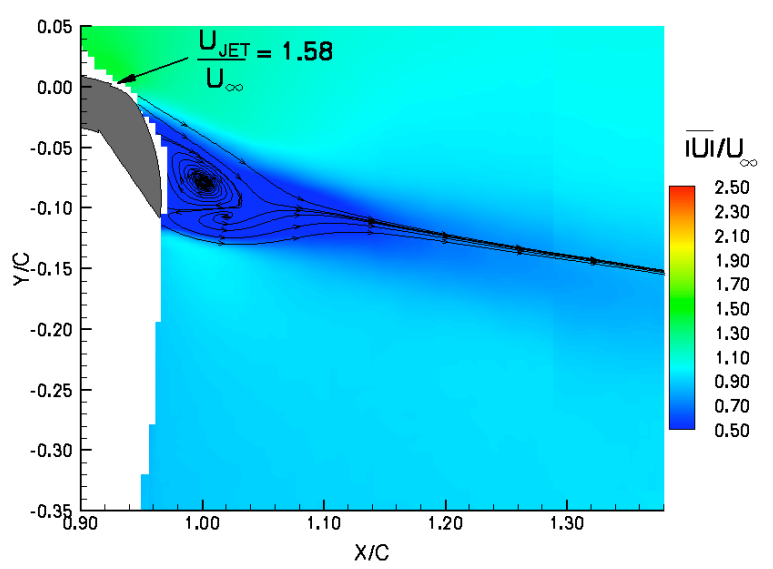

(b) $\mathrm{C} \mu=0.003$

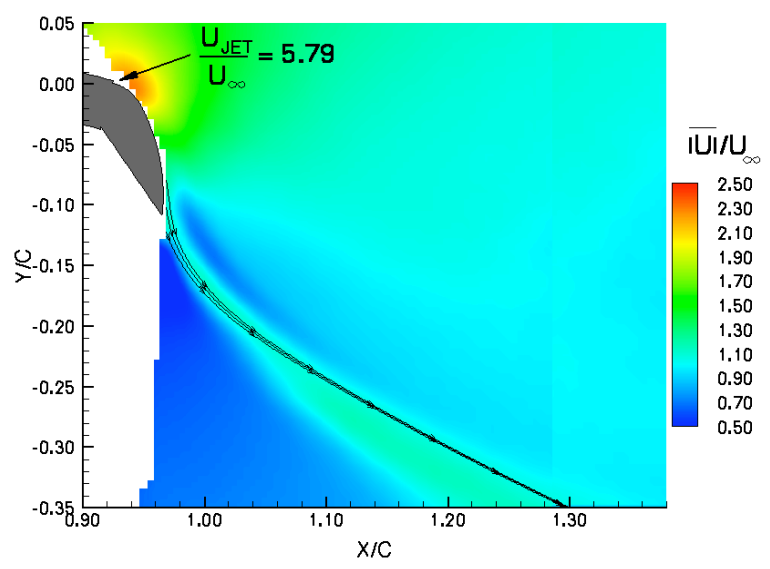

(d) $\mathrm{C} \mu=0.084$

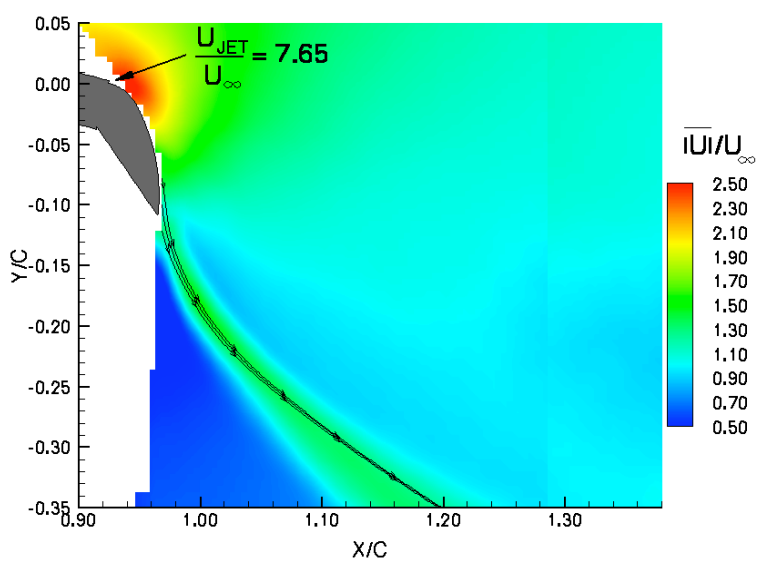

(e) $\mathrm{C} \mu=0.158$

Figure 14. Streamlines and velocity magnitude in near field wake of circulation control flap for varying mass flow, $\mathrm{X} / \mathrm{C}_{\mathrm{JET}}$ EXIT $=0.92, \delta_{\mathrm{FLAP}}=40^{\circ}, \mathrm{h} / \mathrm{C}=0.0010$ and $\mathrm{AOA}=0.0$ degrees. 


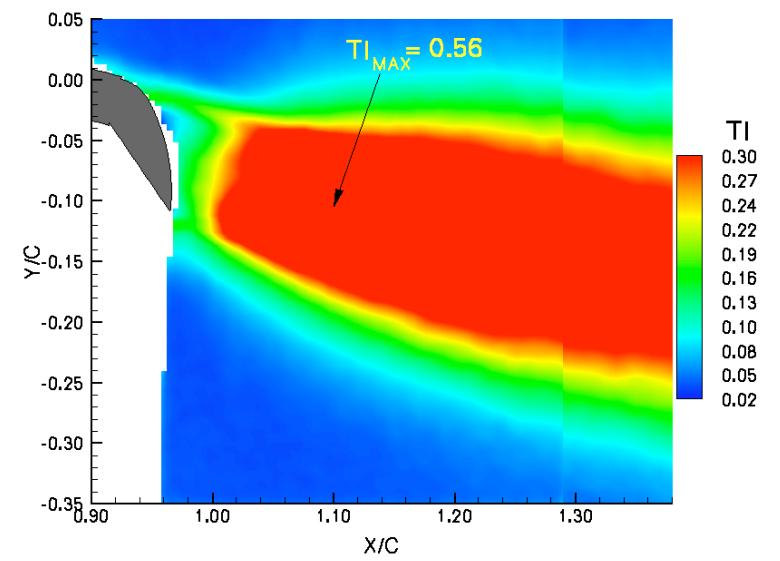

(a) No Blowing

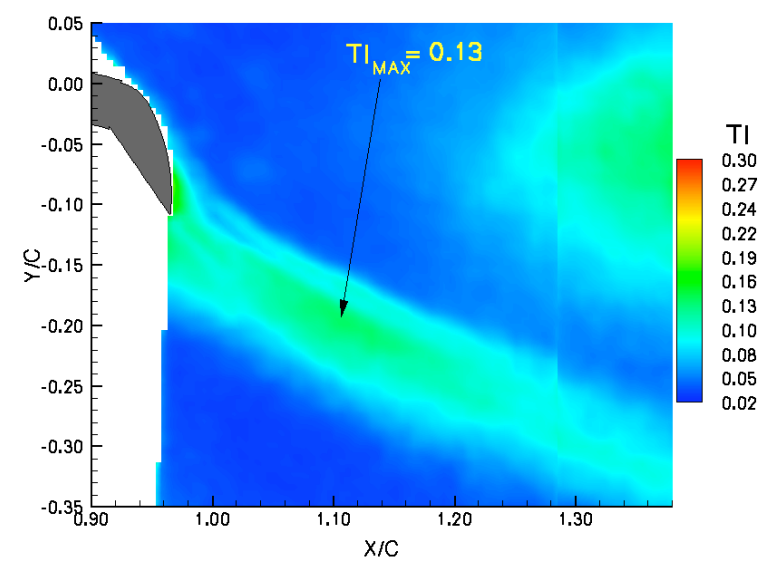

c) $\mathrm{C} \mu=0.029$ (End of separation control)

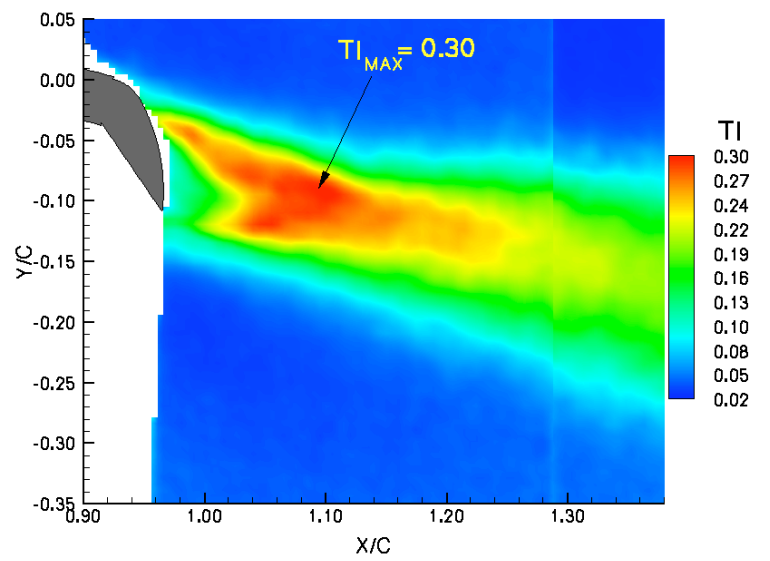

(b) $\mathrm{C} \mu=0.003$

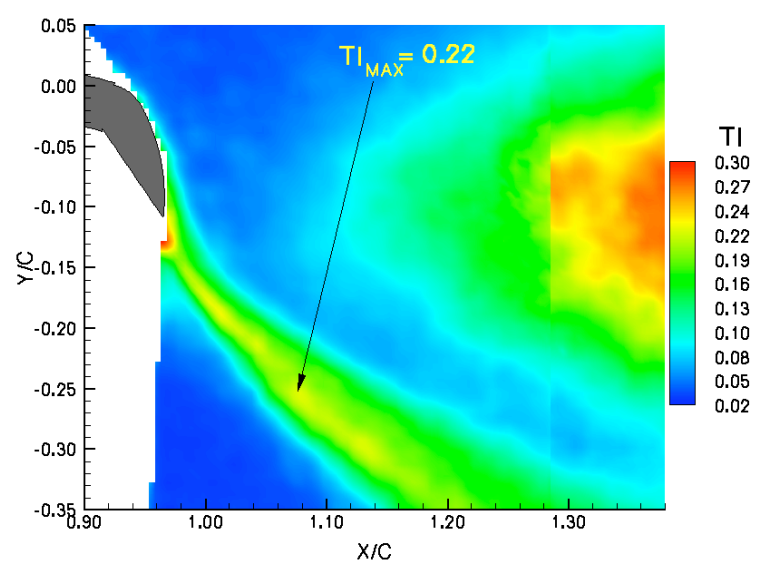

(d) $\mathrm{C} \mu=0.084$

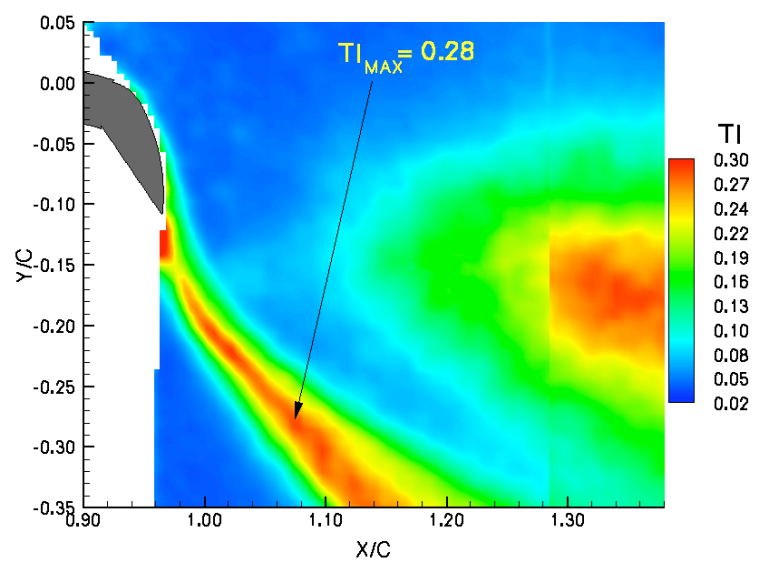

(e) $\mathrm{C} \mu=0.158$

Figure 15. Turbulence intensity characteristics of the circulation control flap with varying mass flow showing maximum jet turbulence intensity location, $X / \mathrm{C}_{\mathrm{JET}} \mathrm{EXIT}_{\mathrm{T}}=0.92, \delta_{\mathrm{FLAP}}=40^{\circ}, \mathrm{h} / \mathrm{C}=0.0010$ and $\mathrm{AOA}=0.0$ degrees. 


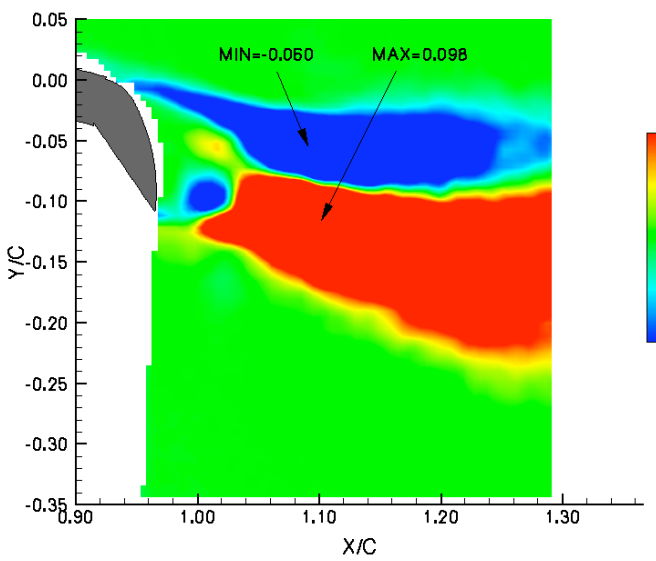

(a) No Blowing

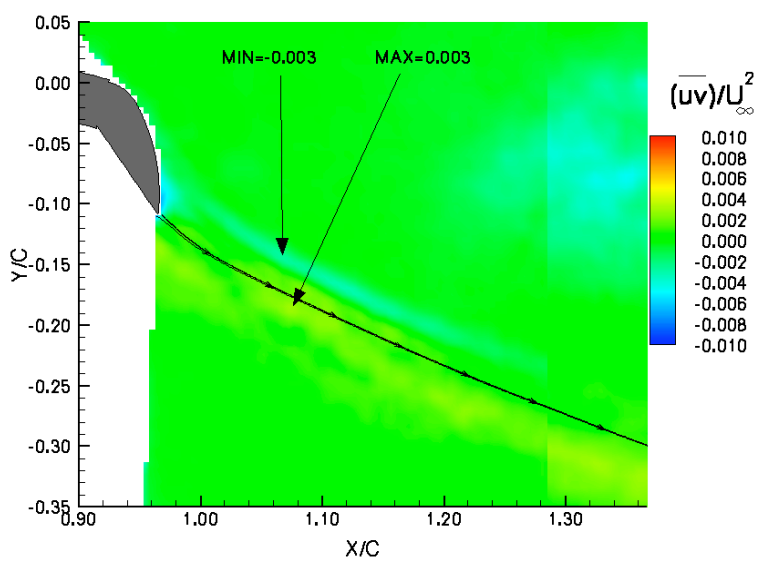

c) $\mathrm{C} \mu=0.029$ (End of separation control)

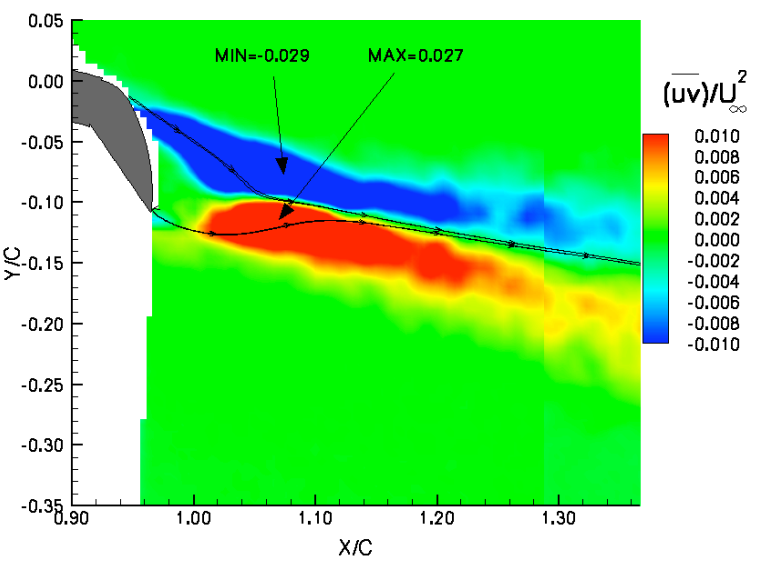

b) $\mathrm{C} \mu=0.003$

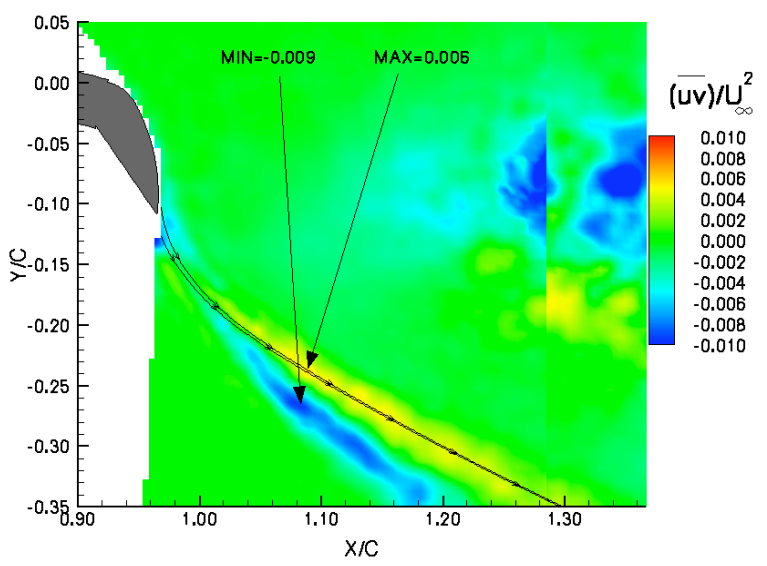

(d) $\mathrm{C} \mu=0.084$

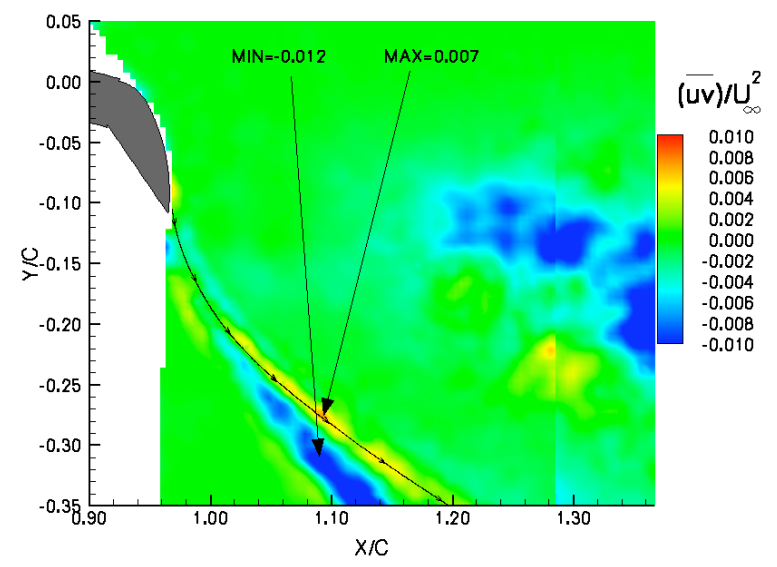

(e) $\mathrm{C} \mu=0.158$

Figure 16. Reynolds shear stress components of near field wake of $\mathrm{CC}$ flap, highlighting the minimum and maximum Reynolds shear stress location for the jet, $\mathrm{X} / \mathrm{C}_{\mathrm{JET}}$ EXIT $=0.92, \delta_{\mathrm{FLAP}}=\mathbf{4 0} 0^{\circ}, \mathrm{h} / \mathrm{C}=\mathbf{0 . 0 0 1 0}$ and $\mathrm{AOA}=0.0$ degrees. 
Examining the jet profiles in the near field of the CC flap identifies an apparent acceleration just downstream of the flap trailing edge. PIV profiles shown in Fig. 17 indicate that the magnitude of the jet peaks at approximately $\mathrm{Y} / \mathrm{C}$ of -0.18 . This is equivalent to 1.5 jet widths from the trailing edge. All of the supercirculation conditions exhibited this phenomenon. This is believed to be an effect of the interaction of the low momentum flow from the lower (or windward) surface of the airfoil. This effect is not observed in the CFD data described in Ref. 11.

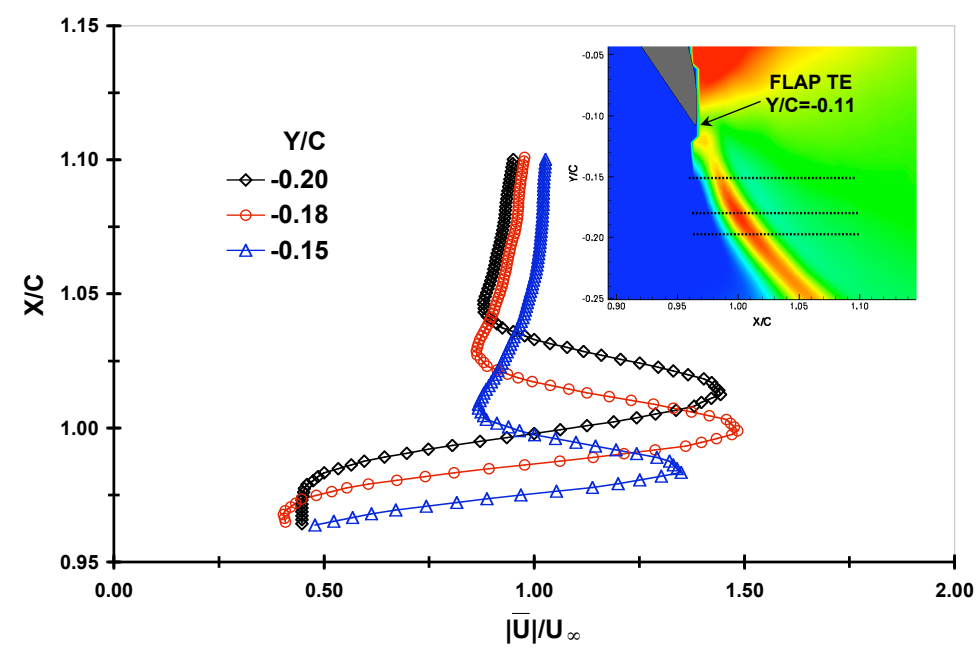

Figure 17 PIV comparison of near field jet characteristics $C \mu=0.158$.

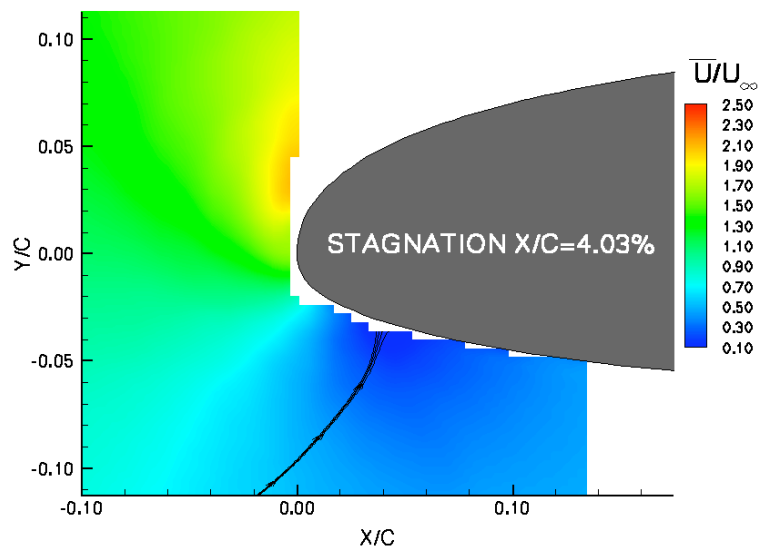

(a) PIV AOA: 0.00

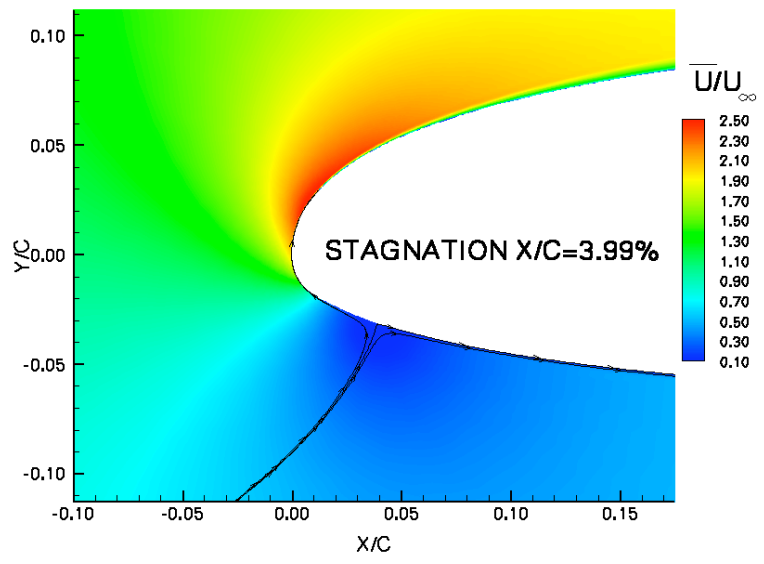

(c) CFD AOA: -5.00

Figure 18. Stagnation variation with angle of attack.

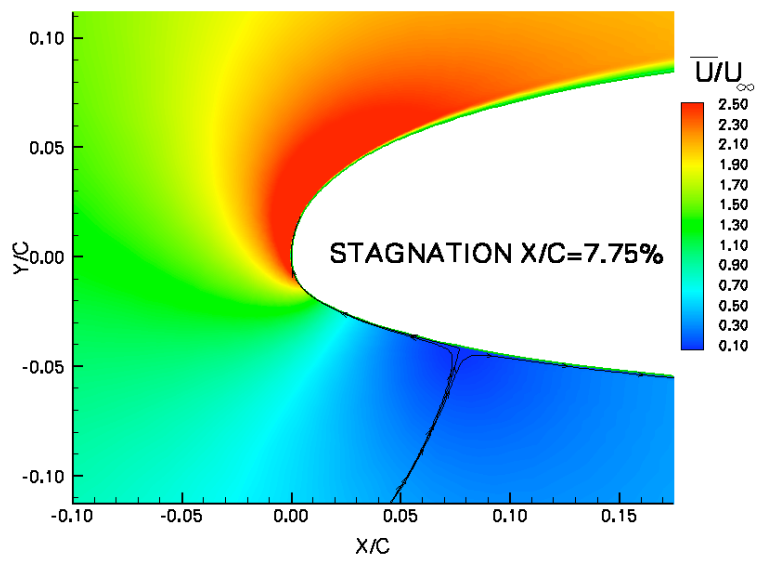

(b) CFD AOA: 0.00

\section{Wind tunnel wall interference}

Several researchers ${ }^{21,22}$ have evaluated the influences of wall interference for circulation control airfoils. Angle of attack corrections for the CC flapped airfoil at a geometric angle of attack of zero degrees and $C \mu=0.158$ were determined to be less than $0.5^{\circ}$ based on classic empirical methods. ${ }^{23,24}$ These values were considered too small, so we used a $2 \mathrm{D}$ unstructured Navier Stokes CFD solution as a guide to estimate the angle of attack correction. Comparison of the CFD and PIV stagnation region for a geometric angle of attack of zero degrees indicated a significant disagreement. Matching the CFD and experimental streamlines shown in Fig. 18a and $18 \mathrm{~b}$ enable the researcher to estimate the angle of attack correction. A $-5.0^{\circ}$ angle of attack adjustment, for the $\mathrm{C} \mu=0.16$ condition, was used to force the computed stagnation streamline to match the experimental stagnation streamline shown in Fig. 18a and 18c. Doing this yields good agreement in the surface pressure distribution shown in Fig. 19. 


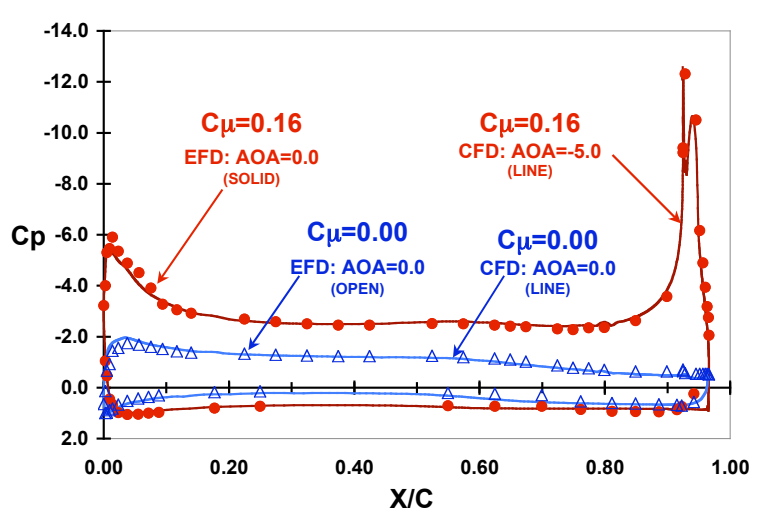

Figure 19. Surface pressure distributions.

3 Hot wire boundary layer profiles on upper surface of airfoil

The experimental model allowed the boundary layer transition to occur naturally, so it was necessary to quantify the character of the boundary layer. Boundary layer profiles shown in Fig. 20a are for several blowing conditions at $50 \%$ chord on the upper surface of the airfoil. The pressure gradients are minimized at this location as shown in Fig. 19. Using law of the wall characteristics all of the blowing data are characteristic of turbulent boundary layers, ${ }^{25}$ Table 1 . This is complemented with the turbulence magnitude data shown in Fig. 20b.

The transition of a wake profile to a jet profile for increasing $\mathrm{C} \mu$ is illustrated in Fig. 21. The large turbulent wake that results from a fully separated flap is reduced in magnitude as the Coanda jet entrains the flow with increasing $C \mu$. The $C \mu=0.03$ condition represents the transition from separation control to super-circulation control. The remnant of the wake is still evident for this condition. As $\mathrm{C} \mu$ continues to increase into the super-circulation region, the jet dominates the flow resulting in thrust $(\mathrm{C} \mu=0.08$ with repeated condition). The turbulence profiles also highlight the efficiency of the Coanda jet turning, shown in Fig. 21b, where the magnitude of the wake/jet profile is smaller than the lower and higher blowing condition. This finding is consistent with PIV data shown in Fig 15.

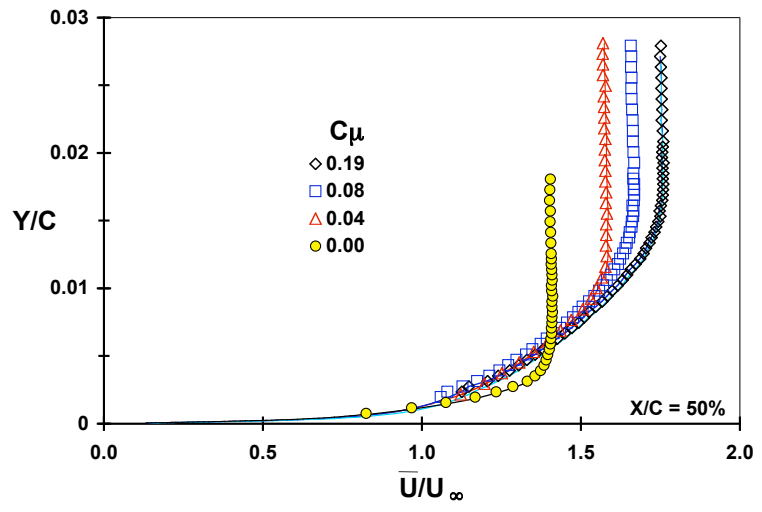

(a) Mean velocity

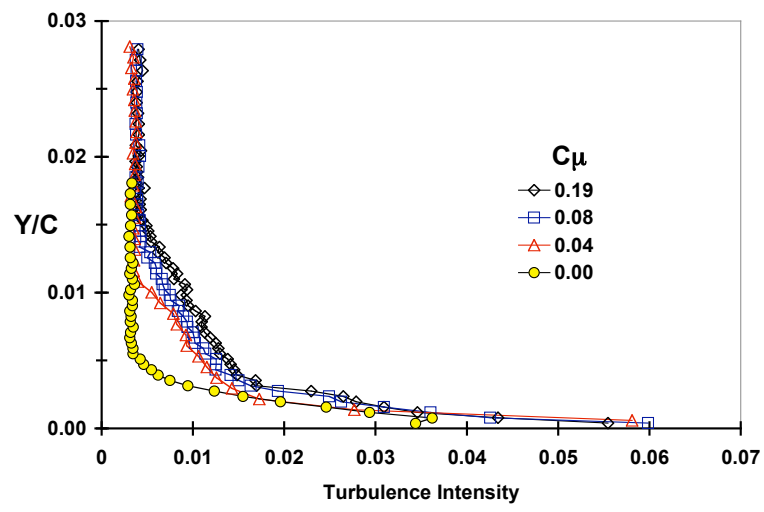

(b) Turbulence magnitudes

Figure 20. Boundary layer profiles for increasing $C \mu, X / C=0.5$ on the upper surface (hot wire data).

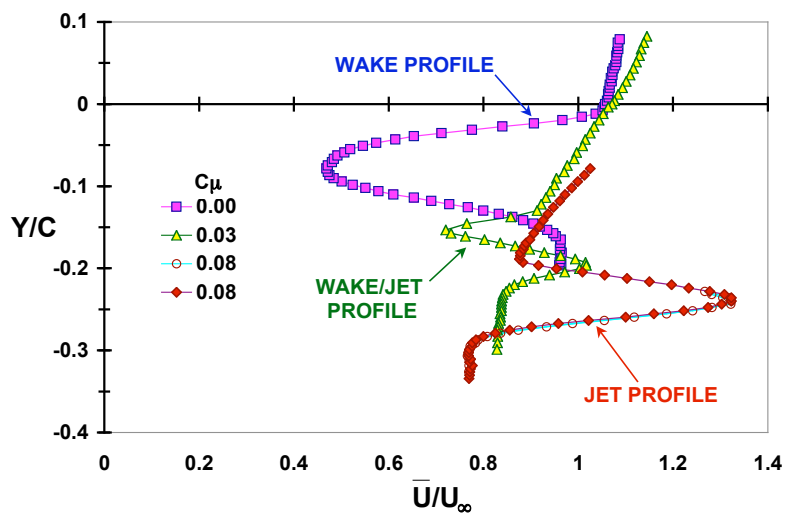

(a) Mean velocity

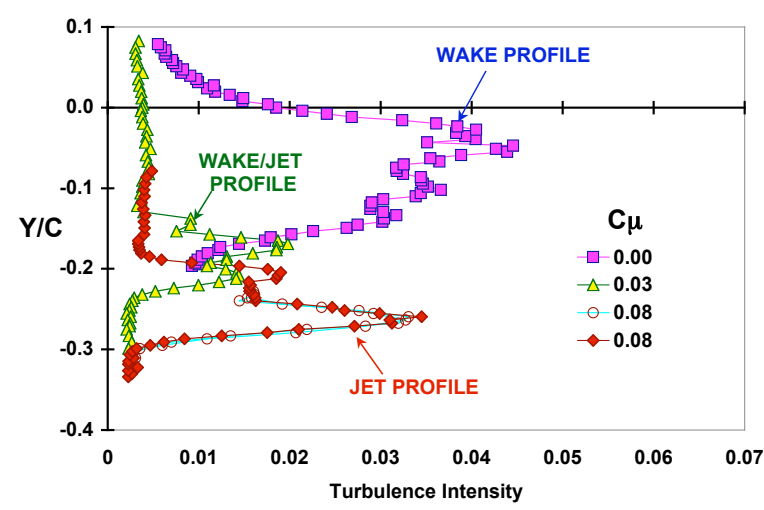

(b) Turbulence magnitudes

Figure 21. Near field wake profiles $\mathrm{x} / \mathrm{C}=1.15$ (hot wire). 


\begin{tabular}{|c|c|c|c|c|c|c|c|c|c|c|}
\hline $\mathrm{C} \mu$ & NPR & Uedge & $\delta$ & Cf & utau & $\delta *$ & Momentum & Energy & Re(theta) & $\begin{array}{c}\text { Shape } \\
\text { Factor }\end{array}$ \\
\hline 0.0000 & 0.0000 & 131.71 & 0.0627 & 0.0037 & 5.6650 & 0.0123 & 0.0069 & 0.0114 & 463 & 1.65 \\
\hline 0.0381 & 1.0937 & 148.48 & 0.1190 & 0.0042 & 6.7634 & 0.0194 & 0.0132 & 0.0230 & 999 & 1.46 \\
\hline 0.0838 & 1.2061 & 155.91 & 0.1506 & 0.0035 & 6.5223 & 0.0260 & 0.0174 & 0.0300 & 1377 & 1.49 \\
\hline 0.1907 & 1.4691 & 164.58 & 0.1671 & 0.0034 & 6.7659 & 0.0288 & 0.0193 & 0.0333 & 1617 & 1.47 \\
\hline
\end{tabular}

Table 1 Boundary layer characteristics of the upper surface location of $\mathrm{X} / \mathrm{C}=0.50$, (hot wire data).

\section{B. Circulation Control 2\% Circular trailing edge Geometry}

\section{PIV data}

PIV measurements were obtained near the circular trailing edge to highlight the separation process on the Coanda surface. Figure 22 shows where PIV data can be correlated to the measured lift performance. Leading edge PIV measurements were not obtained, therefore wall interference corrections were not made for this configuration.

Details of the jet on the Coanda surface could not be obtained due to the reflections of the laser near the surface. However, the jet trajectory can be identified by the velocity magnitudes in the near flow-field as shown in Fig. 23. Turbulence characteristics shown in Fig. 24 highlight the bound region of the jet as it propagates through the flowfield. The extent of the turbulence width is significantly larger than the flapped configuration (Fig.15) in the super-circulation regime due to the enhanced mixing created by the upstream moving jet.

As the blowing is increased the separated flow is entrained and mixed with the jet as shown in Fig. 23a. This is the approximate end of separation control and the transition to super-circulation control. This is confirmed by the minimization of the turbulence intensity identified in Fig. 24a. Continuing to increase the blowing causes separation to move around the Coanda surface $\left(\theta j e t=90^{\circ}\right.$ shown in Fig. $\left.23 \mathrm{~b}\right)$ with a gradual penetration into the on-coming flow-field. As the blowing continues to increase the separation location moves to the lower quadrant of the Coanda surface (shown in Fig. $24 \mathrm{c}-24 \mathrm{e}$ ) causing a local suction on the windward side of the trailing edge. ${ }^{26,27}$ The characteristic of the jet moving upstream could not be completely determined due to the limitations of the PIV laser illumination on the lower surface of the model (see Fig. 9).

To obtain an estimate of the separation location on the Coanda surface, the near field streamlines were extended to a tangent point on the trailing edge. The trajectory of the jet was also extended to the trailing edge to identify the jet separation by the projecting the outer boundaries of the turbulence profiles shown in Fig. 25. This estimate is labeled as $\theta_{\mathrm{JET}}$ in Figs. 24 and 25 and highlights the very sensitive relationship of jet separation and streamline turning efficiency. A maximum separation angle $\theta_{\mathrm{JET}}$ of $122^{\circ}$ was determined for $C \mu=0.3$. This is only a $4^{\circ}$ change from the $\mathrm{C} \mu=0.2$ condition. Using the PIV data, the jet separation angle sensitivity to $C \mu$ can be estimated as:

$$
\theta_{\mathrm{JET}}(\text { degrees })=-166.82(\mathrm{C} \mu)^{2}+145.28(\mathrm{C} \mu)+93.395
$$

This estimate is valid for separation angles greater than $90^{\circ}$ corresponding to $C \mu$ greater than 0.06 . This suggests that the jet separation angle does not exceed $125^{\circ}$ for $\mathrm{C} \mu$ less than 0.4. 


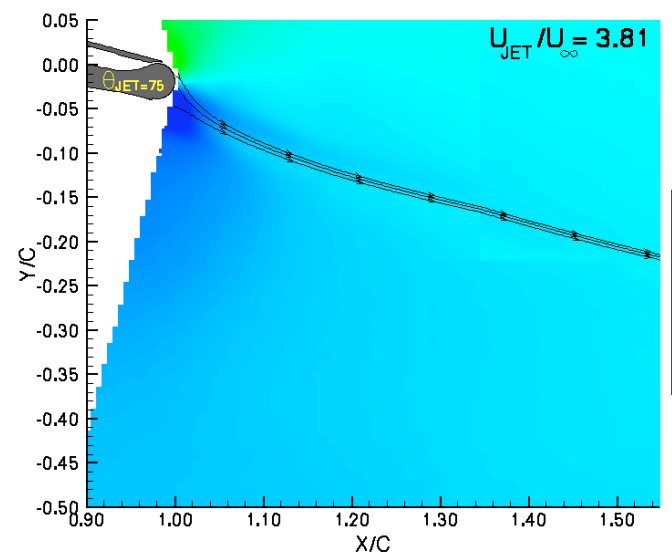

(a) $\mathrm{C} \mu=0.024$

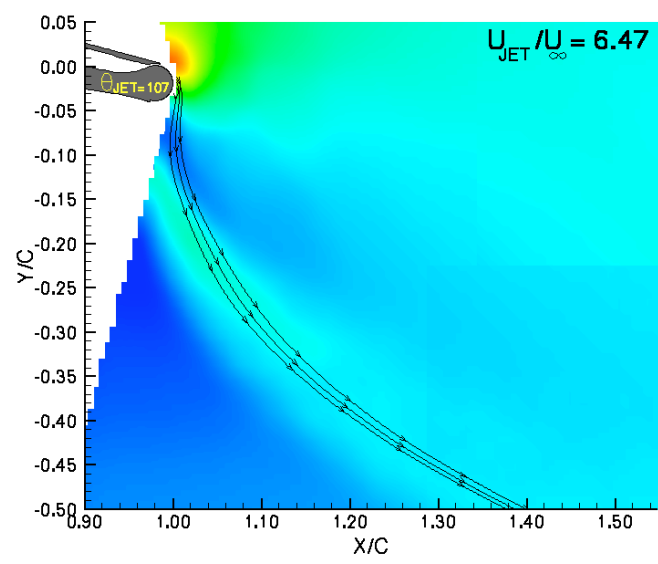

(c) $\mathrm{C} \mu=0.103$

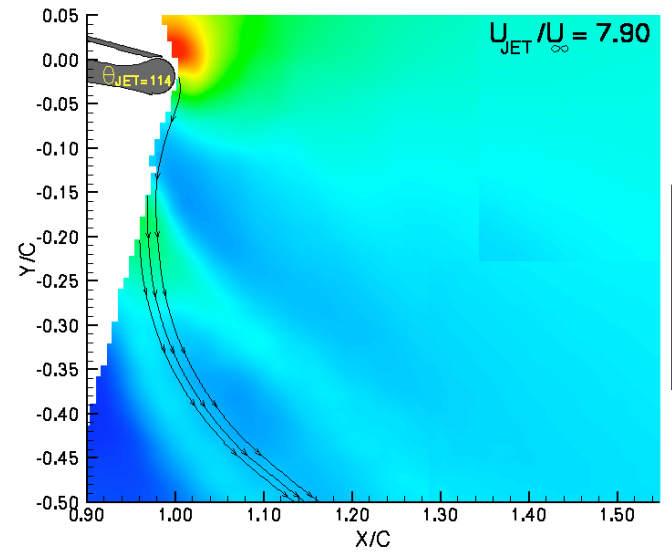

(e) $\mathrm{C} \mu=0.180$

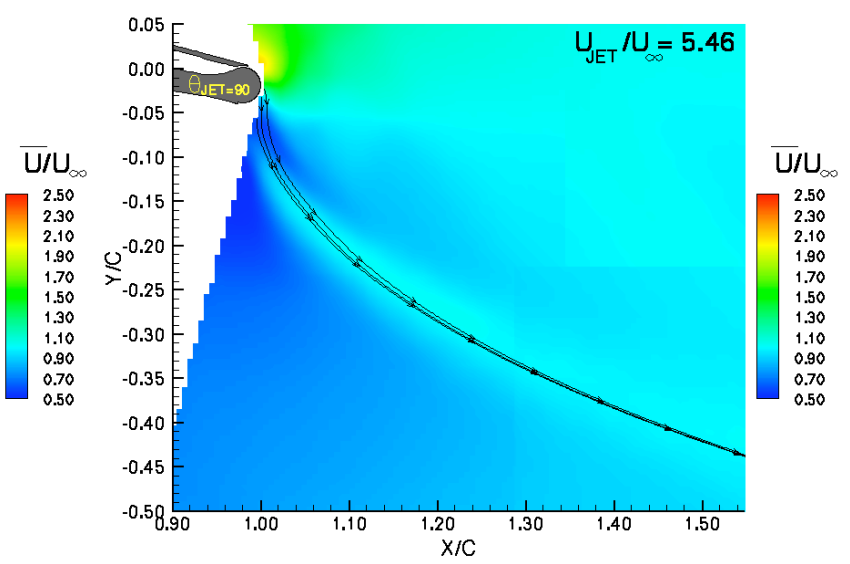

(b) $\mathrm{C} \mu=0.065$

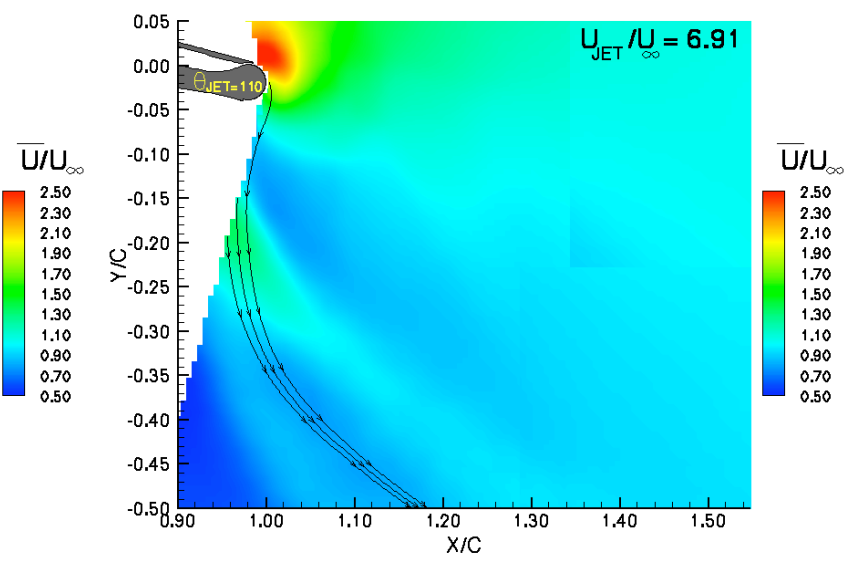

(d) $\mathrm{C} \mu=0.127$

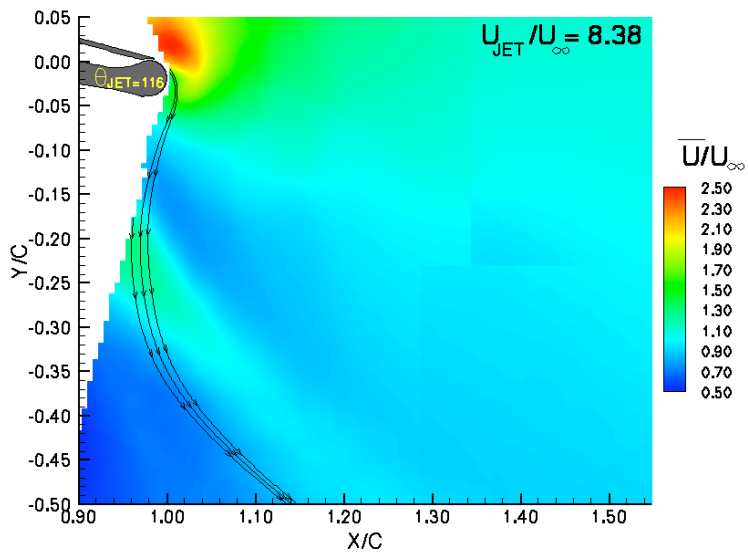

(f) $\mathrm{C} \mu=0.218$

Figure 23. PIV velocity magnitudes for $\mathrm{r} / \mathrm{C}=\mathbf{2 \%}$ circular trailing edge. 


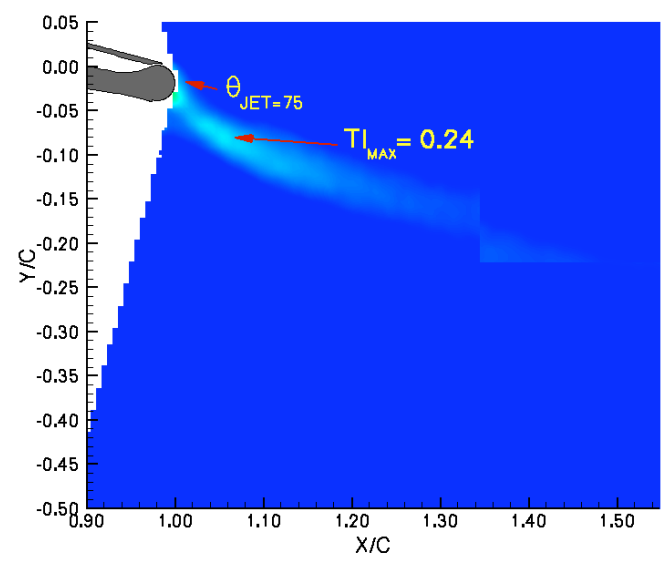

(a) $\mathrm{C} \mu=0.024$

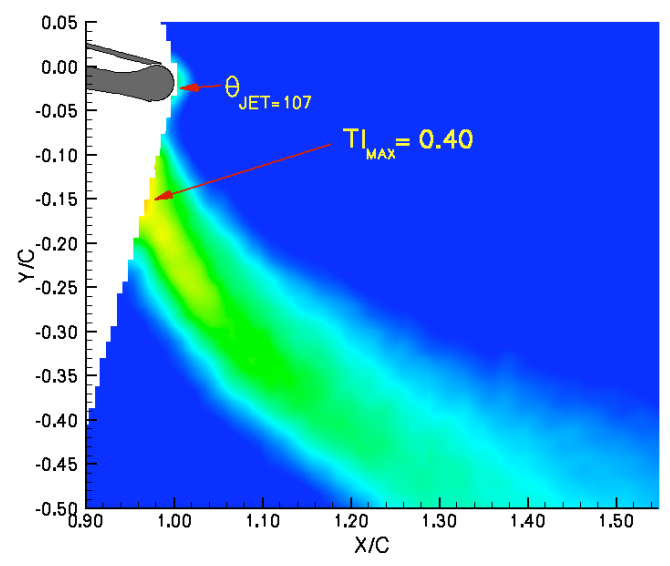

(c) $\mathrm{C} \mu=0.103$

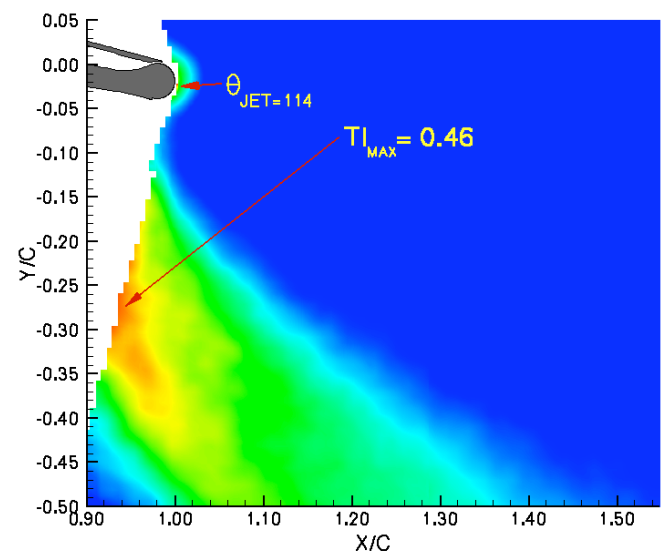

(e) $\mathrm{C} \mu=0.180$

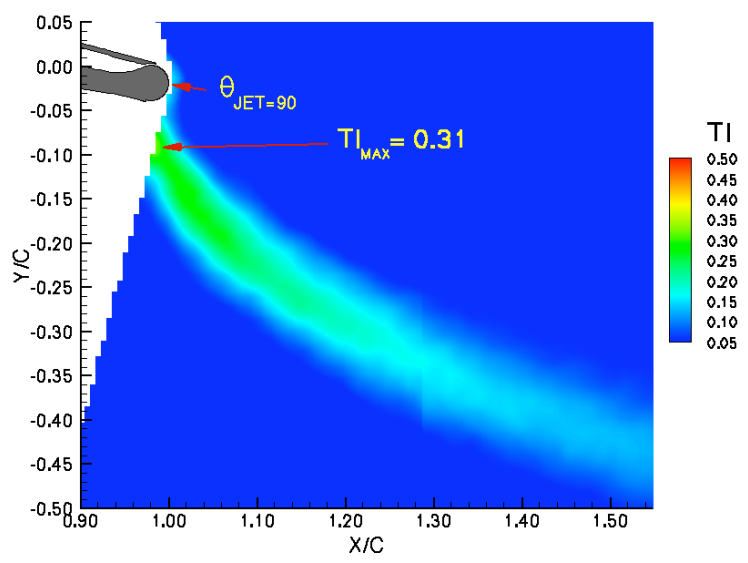

(b) $\mathrm{C} \mu=0.065$

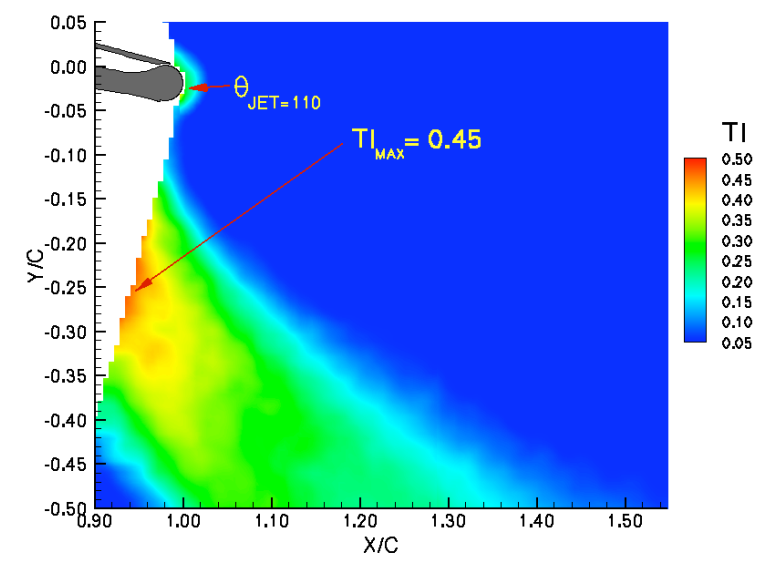

(d) $\mathrm{C} \mu=0.127$

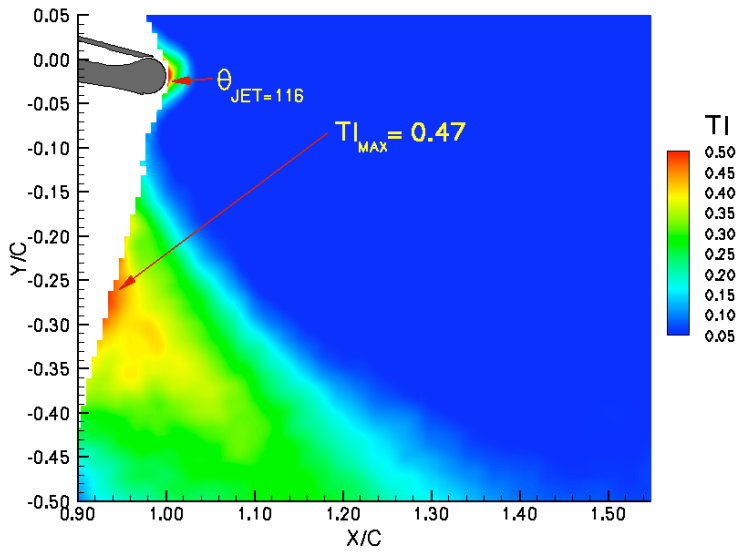

(f) $\mathrm{C} \mu=0.218$

Figure 24. PIV streamlines and turbulence intensity characteristics for $\mathrm{r} / \mathrm{C}=\mathbf{2} \%$ circular trailing edge showing the maximum turbulence intensity location in the jet. 


\section{Conclusions and Recommendations}

The experimental data sets described in this paper highlight the flow field characteristics for two 2D circulation control airfoil configurations. These data sets identify the physical characteristics of typical circulation control airfoils and can provide guidance to developers interested in super-circulation. Salient features of the flow identified in this experiment include:

- Streamline turning and jet characteristics are identified in the near flow field of the two CC models for the separation control regime and the super-circulation regime.

- Jet acceleration in the near flow field of the flap that was evident in the experimental data but in not captured by the CFD computations, warrants further investigation.

- The boundary between the separation control regime and the super-circulation regime in terms of blowing magnitude can be identified when the overall turbulence magnitude in the wake is minimized. This observation implies that the streamlines are most efficiently turned at this boundary.

- Comparing leading edge stagnation streamline data between experiment and CFD can help identify the influence of wall interference that limits streamline turning (i.e. $\alpha$ correction). Adjusting the $\alpha$ in the CFD until the stagnation location matched the experimental location yielded a good comparison of the pressure distribution on the whole airfoil.

Future 2D physics-based circulation control investigations that could be used for CFD validation should consider the following lessons learned from this series of experiments. With respect to the wind tunnel and model scales, we recommend that the model size should be based on a suitable jet exit slot height and an $\mathrm{r} / \mathrm{C}$ large enough to measure the jet characteristics and profiles at the jet exit and on the Coanda surface. Therefore, the slot height should be greater than 0.025 inch (based on minimum hot wire prong tip diameters of 0.0025 inch) and the trailing edge radius should be larger than 0.25 inch to improve the relative measurement resolution near the Coanda surface. This is equivalent to $\mathrm{h} / \mathrm{r}$ of 0.1 and not optimum for $\mathrm{CC}$ airfoil performance. It is also recommended that the Coanda surface should be treated to reduce the reflections that interfere with near surface laser based measurements.

The wind tunnel to model size should be proportioned to the expected high lift condition to minimize the effects of wall interference on streamline turning and model blockage. We suggest a ratio of CC model chord to wind tunnel height be less than 0.15 . We also recommend that the model aspect ratio should be large enough to minimize juncture effects associated with extreme high lift $(A R>3.0)$. In addition, management of the juncture flow between the model and tunnel walls may be carefully done through the application of blowing and/or suction. In all cases with super-circulation, extreme care should be taken in the application of appropriate wind tunnel wall interference corrections.

Some suggestions regarding the experimental measurements for 2D physics-based circulation control investigations are warranted. It is imperative to accurately measure and characterize the blowing momentum coefficient. To obtain a $1 \%$ uncertainty of momentum coefficient (Eq. 2) requires an independent measurement of uncertainty of $1 \%$ for mass flow, jet exit velocity, and the wind tunnel dynamic pressure. The verification of momentum coefficient (Eq. 1) requires a velocity profile at the jet exit and a measurement of density ratio. The influence of the slot height is critical to determine the sectional blowing characteristics of the jet. The slot height should be quantified along the span to vary less than $1 \%$ of the desired slot height. The velocity profile obtained at jet exit is also necessary to characterize the jet as laminar or turbulent. Jet separation location $\left( \pm \theta j \mathrm{jet}<2^{\circ}\right)$ and near field PIV measurements should be confirmed with supplemental hot wire and/or LDV measurements. PIV (or LDV) measurements on the Coanda surface can be improved by seeding the jet and optically magnifying the region. The pixel resolution should be the same order of magnitude of the jet width at the jet separation location. Finally, spanwise flow field measurements should focus on 3D effects that include the extent of the juncture region, the potential vortical flows that are remnants of the internal flow inconsistencies, and/or Gortlier instabilities.

\section{Acknowledgments}

Authors acknowledge Jerome Harris, Ricky Clark, Richard White, and Al Barnes for their exceptional skill and technical support in this experimental study. 


\section{References}

${ }^{1}$ Joslin, R.D. (ed), Jones, G.S. (e d), Application of Circulation Control Technology, Progress in Astronautics and Aeronautics, Vol. 212, May, 2006

${ }^{2}$ Rich, P., McKinley, R,J., Jones, G.S., “Circulation Control in NASA’s Vehicle Systems”, NASA CP-205-213509 (part 1), June 2005.

${ }^{3}$ Jones, G.S. (ed), Joslin, R.D. (ed), Procedings of the NASA/ONR 2004 Circulation Control Workshop, NASA CP2005-213509 (parts 1 and 2), June 2005.

${ }^{4}$ Englar, R. J., Smith, M. J., Kelley, S. M., and Rover, R. C. III, “Application of Circulation Control Technology to Advanced Subsonic Transport Aircraft, Part I: Airfoil Development,” AIAA Paper No. 93- 0644, AIAA Journal of Aircraft, Vol. 31, No. 5, pp. 1160-1168, Sept-Oct. 1994.

${ }^{5}$ Harris, M. H., J. H. Nichols Jr., R. J. Englar, and G. G. Huson, "Development of the Circulation Control Wing/Upper Surface Blowing Powered-Lift System for STOL Aircraft," Paper No. ICAS-82-6.5.1, in Proceedings of the ICAS/AIAA Aircraft Systems and Technology Conference, Seattle, August 22-27, 1982.

${ }^{6}$ Englar, R. J., "Circulation Control Pneumatic Aerodynamics: Blown Force and Moment Augmentation and Modification; Past, Present and Future," AIAA Paper 2000-2541, presented at AIAA Fluids 2000 Meeting, Denver, CO, June 19-22, 2000.

${ }^{7}$ Abramson, J., and Rogers, E.O., "High-Speed Characteristics of Circulation Control Airfoils,” AIAA-83-0265, January 1983

${ }^{8}$ Englar, R. J., "Circulation Control Pneumatic Aerodynamics: Blown Force and Moment Augmentation and Modification; Past, Present and Future," AIAA Paper 2000-2541, presented at AIAA Fluids 2000 Meeting, Denver, CO, June 19-22, 2000.

${ }^{9}$ Wood, N.J., and Nielsen, J.N., “Circulation Control Airfoils Past, Present, Future,” Paper AIAA 85-0204, AIAA 23rd Aerospace Sciences Meeting, Reno, Nevada, 1985

${ }^{10}$ Sellers, W.L., Jones, G.S., and Moore, M.D., "Flow Control Research at NASA Langley in Support of High-Lift Augmentation," AIAA-2002-6006

${ }^{11}$ Lee-Rausch, E.M,. Vatsa, V.N., Rumsey, C.L., "Computational Analysis of Dual Radius Circulation Control Airfoils", AIAA 2006-3012, June 2006

${ }^{12}$ Swanson, R., Rumsey, C., "Numerical Issues for Circulation Control Calculations”, AIAA 2006-3008, June 2006

${ }^{13}$ Swanson, R.C., Rumsey, C.L., Anders, S.G., "Progress Towards Computational Method for Circulation Control Airfoils," AIAA 2005-0089, January 2005

${ }^{14}$ Englar, R. J. and Williams, R.M., "Test Techniques for High Lift Two- Dimensional Airfoils with Boundary Layer and Circulation Control for Application to Rotary Wing Aircraft," Canadian Aeronautics and Space Journal, Vol. 19, No. 3, pp. 93-108,Mar 1973.

${ }^{15}$ Cagle, C.M., Jones, G.S., “A Wind Tunnel Model to Explore Unsteady Circulation Control for General Aviation Applications", AIAA 2002-3240, June 2002 
${ }^{16}$ Sellers, W.L.,III, Kjelgaard, S.O., "The Basic Aerodynamics Research Tunnel - A Facility Dedicated to Code Validation”, AIAA-88-1997, May 1988

${ }^{17}$ Jones, G.S., Viken, S.A., Washburn, A.E., Jenkins, L.N., \& Cagle, C.M., “An Active Flow Circulation Controlled Flap Concept for General Aviation Applications”, AIAA 2002-3157, June 2002

${ }^{18}$ Jones, G.S., Englar, R.J., “Advances in Pneumatic-Controlled High-Lift Systems Through Pulsed Blowing, AIAA 2003-3411, June 2003

${ }^{19}$ Raffel, M., Willert, C., Kompenhans, J., Particle Image Velocimetry, A Practical Guide, Springer, New York, N.Y., Chapter 5, 1998

${ }^{20}$ K. T. Christensen, Experiments in Fluid, 36 (2004) p484-497

${ }^{21}$ J.E. Hackett, "Tunnel-Induced Gradients and their Effect on Drag”, AIAA Journal, Vol. 34, No. 12 pp 2575-2581, 1996

${ }^{22}$ Owen, F. K. “Application of Laser Velocimetry to Unsteady Flows in Large Scale High Speed Wind Tunnels". International Congress on Instrumentation in Aerospace Simulation Facilities, IEEE Publication 83CH1954-7, 1983

${ }^{23}$ A. Krynytzky, J.E. Hackett, Wind Tunnel Wall Corrections, AGARDograph 336, Chapter 2, October 1998

${ }^{24}$ Allan, H.J., and Vincenti, W.G., "Wall Interference in a Two-Dimensional-Flow Wind Tunnel with Consideration of the Effect of Compressibility, NACA Report 782, 1944

${ }^{25}$ H. Schlichting, Boundary Layer Theory, (seventh edition), McGraw Hill, New York, N.Y., pp. 671-690, 1979

${ }^{26}$ Rogers, E.O., Donnelly, M.J., "Characteristics of a Dual-Slotted Circulation Control Wing of Low Aspect Ratio Intended for Naval Hydrodynamic Applications,” AIAA 2004-1244, January 2004

${ }^{27}$ Imber, R. D., and Rogers, E. O., "Investigation of a Circular Planform Wing with Tangential Fluid Ejection," AIAA Paper 96-0558, Jan. 1996

${ }^{28}$ Rae, W.H.,Jr., Pope, A., Low-Speed Wind Tunnel Testing, Second Edition, Chapter 6, John Wiley \& Sons, New York, N.Y., 1984 